\title{
Cannabinoid Receptors in the Bed Nucleus of the Stria Terminalis Control Cortical Excitation of Midbrain Dopamine Cells In Vivo
}

\author{
Léma Massi, ${ }^{1,2 \star}$ Izaskun Elezgarai, ${ }^{3 \star}$ Nagore Puente,,${ }^{1,2,3}$ Leire Reguero, ${ }^{3}$ Pedro Grandes, ${ }^{3}$ Olivier J. Manzoni, ${ }^{1,2^{\dagger}}$ and \\ François Georges ${ }^{1,2 \dagger}$ \\ Pathophysiology of Synaptic Plasticity Group, INSERM, U862, ${ }^{1}$ Neurocentre Magendie and ${ }^{2}$ Université de Bordeaux, Bordeaux, F-33000, France, and \\ ${ }^{3}$ Department of Neurosciences, Faculty of Medicine and Dentistry, Basque Country University, 699-48080 Bilbao, Spain
}

\begin{abstract}
The endocannabinoid system is involved in multiple physiological functions including reward. Cannabinoids potently control the activity of midbrain dopamine cells, but the contribution of cortical projections in this phenomenon is unclear. We show that the bed nucleus of the stria terminalis (BNST) efficient relays cortical excitation to dopamine neurons of the ventral tegmental area (VTA). Anatomical and in vivo electrophysiological evidence demonstrate that excitatory projections arising exclusively from the infralimbic cortex converge on BNST neurons, which in turn project to and excite $>80 \%$ VTA dopamine cells. At the ultrastructural level, cannabinoid type 1 receptors are detected within the BNST on axon terminals arising from the infralimbic cortex. We found that intra-BNST infusion of a cannabinoid agonist inhibits the firing of dopamine cells evoked by stimulation of the infralimbic cortex. Our data identify a new neuronal substrate for the actions of cannabinoids in the reward pathway.
\end{abstract}

Key words: cannabinoid; prefrontal cortex; bed nucleus of the stria terminalis; ventral tegmental area; dopamine cells; reward

\section{Introduction}

Midbrain dopamine (DA) neurons are necessary for processing naturally rewarding stimuli as well as self-administration of drugs of abuse (Grace et al., 2007). Through activation of cannabinoid type1 receptors (CB1-R), the endocannabinoid system is involved in multiple physiological functions in the CNS mainly because it participates in modulation of neuronal excitability and various forms of synaptic plasticity (for review, see Maldonado et al., 2006). Accumulating evidence points to a prominent role of the endocannabinoid system in reward-related behaviors. The present study tests the hypothesis that cannabinoids regulate synaptic inputs to ventral tegmental area (VTA) DA neurons.

Neuroanatomical (Sesack and Pickel, 1992; Charara et al., 1996; Omelchenko and Sesack, 2005, 2007) and electrophysiological (Murase et al., 1993; Georges and Aston-Jones, 2002; Floresco et al., 2003; Lodge and Grace, 2006) evidence indicates that excitatory afferents to the VTA arise in the medial prefrontal cortex (mPFC), the bed nucleus of the stria terminalis [BNST; a

\footnotetext{
Received May 21, 2008; revised Aug. 19, 2008; accepted Sept. 4, 2008.

This work was supported by Grants from INSERM, Mission interministèrielle de lutte contre les drogues et la toxicomanie/Institut National du Cancer/INSERM 2006, Région Aquitaine, ANR-06-NEUR-043-01, ANR Neurologie et psychiatrie $n^{\circ}$ RPV06092GSA, and the Basque Country Government Grant GIC07/70-IT-432-07. We thank Dr. G. Aston-Jones for discussions and comments on this manuscript. We thank Dr. G. Marsicano for providing the CB1 null mice. We thank Marja Sepers for her editorial assistance.

*L.M. and I.E. contributed equally to this work.

${ }^{\dagger}$ O.J.M. and F.G. share seniority.

Correspondence should be addressed to either of the following at their above addresses: Olivier J. Manzoni, E-mail: olivier.mazoni@inserm.fr; or François Georges, E-mail: francois.georges@inserm.fr. D0I:10.1523/JNEUROSCI.2291-08.2008

Copyright $\odot 2008$ Society for Neuroscience ～0270-6474/08/2810496-13\$15.00/0
}

component of the extended amygdala (ExtA)], and laterodorsal and pedunculopontine tegmental nuclei, suggesting that midbrain DA neuron activity is mainly controlled by few structures.

We reported previously that the BNST has a major excitatory influence on DA cell firing within VTA (Georges and AstonJones, 2002). This excitatory projection has been implicated in cocaine and food self-administration (Dumont et al., 2005; Grueter et al., 2006), drug-seeking (Aston-Jones and Harris, 2004), and stress-induced relapse to cocaine (Erb et al., 2001). The BNST integrates information from stress input pathways and subsequently regulates both stress output and reward pathways (Herman and Cullinan, 1997). Although the endocannabinoid system participates in these functions, the subcellular localization of CB1-R in the BNST, and the effect of their activation on BNST neuronal activity are unknown. We hypothesized that the CB1-R regulates the excitatory synaptic projections from the BNST to the VTA DA neurons. The BNST and the infralimbic cortex (ILCx) play an important role in regulating the adaptative responses to emotional stress (Spencer et al., 2005) and rewarddirected behaviors (Seamans et al., 1995). Despite its important role in DA cells mediated functions, the ILCx accounts for a mere $10 \%$ of the prefrontal excitatory projections to the VTA (Geisler et al., 2007). The neural circuits underlying the ILCX-dependent modulation of DA neurons needs to be determined to fully decipher the mechanisms underlying DA cell activity.

In the present study, we used tract tracing approaches, electron microscopy, and in vivo electrophysiological recordings to demonstrate that the BNST actively relays the excitatory drive from the ILCx to VTA DA neurons, and that intra-BNST CB1-R 
stimulation inhibits the firing of dopamine cells evoked by stimulation of the ILCx. Together, our findings further recognize the prominent role of the BNST in the control of DA cells excitability and identify a new neuronal substrate for the effects of cannabinoids on reward-related behaviors.

\section{Materials and Methods}

Animals. Animal experiments met the criteria of the European Communities council Directive (86/609/EEC; authorization number, 3307 017) and the United States National Institutes of Health Guide for the Care and Use of Laboratory Animals. Ninety-two Sprague Dawley rats (275-300 g; Elevage Janvier) were used. Rats were housed three or four per cage under controlled conditions $\left(22-23^{\circ} \mathrm{C}, 40 \%\right.$ relative humidity, $12 \mathrm{~h}$ light/dark illumination cycle; lights on from 7:00 A.M. to 7:00 P.M.), were acclimatized to laboratory conditions 1 week before the experiment, and were allowed ad libitum access to commercial chow and tap water. The CB1$\mathrm{R}^{-1-}$ mice [CB1-R knock-out (KO)] were a generous gift from Dr. G. Marsicano (INSERM U862, Bordeaux, France).

Surgery. Stereotaxic surgeries for electrophysiology and tract-tracing experiments were performed under halothane anesthesia as described previously (Georges and Aston-Jones, 2002). Recording, stimulating, or ejection pipettes were inserted into the ILCx, the BNST, or the VTA with the skull flat at the following coordinates: ILCx: $+3.0 \mathrm{~mm}$ from bregma, $0.5 \mathrm{~mm}$ from midline, $4.5 \mathrm{~mm}$ from brain surface; BNST: $-0.3 \mathrm{~mm}$ from bregma; $1.5 \mathrm{~mm}$ from midline, $6.0-7.5 \mathrm{~mm}$ from brain surface; VTA: $-5.3 \mathrm{~mm}$ from bregma, $0.8 \mathrm{~mm}$ from midline, $8.2 \mathrm{~mm}$ from brain surface.

Electrical stimulation of the ILCX. Bipolar electrical stimulation of the IL cortex was conducted with a concentric electrode $(250 \mu \mathrm{m}$ diameter overall, $100 \mu \mathrm{m}$ diameter inner electrode which extended $100 \mu \mathrm{m}$ beyond the outer electrode; Phymep). This electrode was inserted into the IL cortex (supplemental Fig. 1, available at www.jneurosci.org as supplemental material). Electrical stimulation (0.1-1.0 mA for BNST recordings, up to $2.0 \mathrm{~mA}$ for VTA DA recordings, $0.5 \mathrm{~Hz}, 0.5 \mathrm{~ms}$ duration pulses) was administered using a square pulse stimulator (CED 1401, SPIKE 2; Cambridge Electronic Design) and stimulus isolator (DS3; Digitimer).

BNST recordings. A glass micropipette (tip diameter, $1-2 \mu \mathrm{m} ; 10-15$ mohm) filled with a $2 \%$ pontamine sky blue solution in $0.5 \mathrm{~m}$ sodium acetate was lowered into the BNST. Through these electrodes, the extracellular potential was recorded with an Axoclamp2B amplifier in the bridge mode versus a reference electrode maintained in contact with the skull by a sponge moistened with a $0.9 \% \mathrm{NaCl}$ solution. The extracellular potential amplified $10 \times$ by the Axoclamp2B amplifier was further amplified $100 \times$ and filtered (low-pass filter at $300 \mathrm{~Hz}$ and high-pass filter at $10 \mathrm{kHz}$ ) via a differential AC amplifier (model 1700; A-M Systems). Spikes of single neurons were discriminated, and digital pulses were led to a computer for on-line data collection using a laboratory interface and software (CED 1401, SPIKE 2; Cambridge Electronic Design). After isolating a single BNST neuron, prestimulation spontaneous activity was recorded to establish baseline activity for at least $5 \mathrm{~min}$. Subsequently, single pulses were delivered to the IL cortex every $2 \mathrm{~s}$. At least 100 trials were administered per cell.

BNST recordings and pharmacological microinfusions. Double-barrel pipettes (Georges and Aston-Jones, 2002) were used to record BNST spike activity while simultaneously microinjecting one of the following: a mixture of $100 \mu \mathrm{M}$ amino-5-phosphonopentanoic acid (AP5) and $50 \mu \mathrm{M}$ 6-cyano-7nitroquinoxaline-2,3-dione (CNQX), $1 \mathrm{~mm}$ picrotoxin, or artificial CSF (aCSF). All drugs were dissolved in aCSF. Electrical stimulation of the VTA was used to test for antidromic activation of BNST neurons using high-frequency following collision methods, as described previously (Georges and Aston-Jones, 2002). A bipolar concentric stimulation electrode was inserted into the VTA and stimulation of the VTA and recordings in the BNST using methods described above. Driven impulses were considered antidromic if they met the following criteria: (1) constant latency of spike response, (2) driving by each paired stimulus pulses at frequencies of $100 \mathrm{~Hz}$ or greater, and (3) collision of driven spikes by spontaneous impulses occurring within a critical interval ap- proximately equal to the sum of the refractory period plus the driving latency. A measure of the axonal refractory period was obtained by determining the minimum interval between paired stimuli producing two action potential $100 \%$ of the time. The delay at which the second response disappeared corresponded to the absolute refractory period of that particular unit. Absolute refractory period measurement and collision of driven spikes with spontaneous impulses were conducted with stimulation amplitudes of 1.5-2.0 $\times$ threshold for driving.

Local chemical manipulation of the BNST. An injection pipette (tip, $<50 \mu$ m diameter) was filled with a mixture of glutamatergic antagonists (AP5, $100 \mu \mathrm{M}$; CNQX, $50 \mu \mathrm{M}$ ) or WIN 55, 212-2 (WIN, $500 \mu \mathrm{M}$ ), and was lowered into the BNST. Glutamatergic antagonists or WIN 55212-2 were microinjected into the BNST using brief pulses of pneumatic pressure (Picospritzer; General Valve). In all experiments, a total volume of 20-30 $\mathrm{nl}$ was infused by visual observation of the meniscus $>15 \mathrm{~s}$ between injections; the absence of meniscus movement showed that no spontaneous leakage occurred with this type of pipette. Two injections at a single BNST site were typically given at an interval $>45 \mathrm{~min}$. All injection sites were marked by iontophoretic ejection of pontamine sky blue from an adjacent micropipette barrel.

Dopamine neuron recordings. A glass micropipette (tip diameter, 2-3 $\mu \mathrm{m} ; 4-6 \mathrm{mohm}$ ) filled with a $2 \%$ pontamine sky blue solution in $0.5 \mathrm{M}$ sodium acetate was lowered into the VTA. DA neurons were identified according to well-established electrophysiological features (Grace and Bunney, 1984), these included the following: (1) an action potential width $\geq 1.1 \mathrm{~ms}$ (measured from the start of action potential to the negative trough); (2) slow spontaneous firing rate (2-9 impulses per second); (3) single and burst spontaneous firing patterns (characterized by spikeamplitude decrement); (4) inhibition of spontaneous activity by DA receptor agonists and subsequent reversal by DA receptor antagonists (data not shown). Signals were amplified and filtered as described above. Spikes of single neurons were discriminated, and digital pulses were led to a computer for on-line data collection using a laboratory interface and software (CED 1401, SPIKE 2; Cambridge Electronic Design).

After isolating a single VTA neuron, prestimulation spontaneous activity was recorded to establish baseline activity for at least $5 \mathrm{~min}$. Subsequently in electrical stimulation experiments, single pulses were delivered to the ILCx every $2 \mathrm{~s}$. At least 100 trials were administered per cell. In experiments with chemical manipulation of the BNST, microinfusions were delivered for $30 \mathrm{~s}$ after recording at least $5 \mathrm{~min}$ of (1) baseline activity from a VTA DA neuron and (2) evoked activity of VTA DA neuron by stimulation of the ILCx. Only one microinfusion was made per cell, and no $>2$ microinfusions were made in the same site.

Histology. At the end of each recording penetration, the electrode placement was marked with an iontophoretic deposit of pontamine sky blue dye (negative continuous current at $20 \mu \mathrm{A}$ for $12-15 \mathrm{~min}$ ) (Fig. $1 \mathrm{~B}$, top). To mark electrical stimulation sites, $10 \mu \mathrm{A}$ of positive current was passed through the stimulation electrode for $1 \mathrm{~min}$ (Fig. $1 \mathrm{~B}$, bottom; supplemental Fig. 1, available at www.jneurosci.org as supplemental material). After dye ejection, brains were removed and snap-frozen in a solution of isopentane at $-70^{\circ} \mathrm{C}$. The tissue was sectioned into $25 \mu \mathrm{m}-$ thick coronal slices, mounted, and stained with neutral red to enable histological determination of recording and stimulating electrode sites. Representative locations of different classes of BNST neurons and stimulating electrodes are presented in Figures 1 and 2.

Pharmacological treatments. The jugular vein was cannulated for intravenous administration of pharmacological agents. The DA receptor agonist apomorphine hydrochloride $(0.1 \mathrm{mg} / \mathrm{kg}$; Sigma-Aldrich) and the $\mathrm{D}_{2}$ DA receptor antagonist eticlopride $(0.1 \mathrm{mg} / \mathrm{kg}$; Sigma-Aldrich $)$ were prepared in $0.9 \%$ sterile $\mathrm{NaCl}$ and were used to characterize pharmacologically VTA DA neurons. The cannabinoid receptors agonist WIN 55, 212-2 (WIN; Tocris Bioscience) and the CB1-R antagonist SR141617A (SR, a generous gift from sanofi-aventis) were dissolved in vehicle solution (VEH, 1.25\% Cremophor EL;Sigma-Aldrich) in 0.05\% dimethyl sulfoxide (Sigma-Aldrich) in saline (for intravenous injections) or aCSF (for intra-BNST microinfusions). Picrotoxin, AP5, and CNQX were from Sigma-Aldrich. For intra-BNST microinfusions, AP5 (100 $\mu \mathrm{M})$, CNQX $(50 \mu \mathrm{M})$, picrotoxin $(1 \mathrm{mM})$, and GABA (1 M) were dissolved in aCSF. For intravenous injections, the dose of SR141716A was $1 \mathrm{mg} / \mathrm{kg}$ 

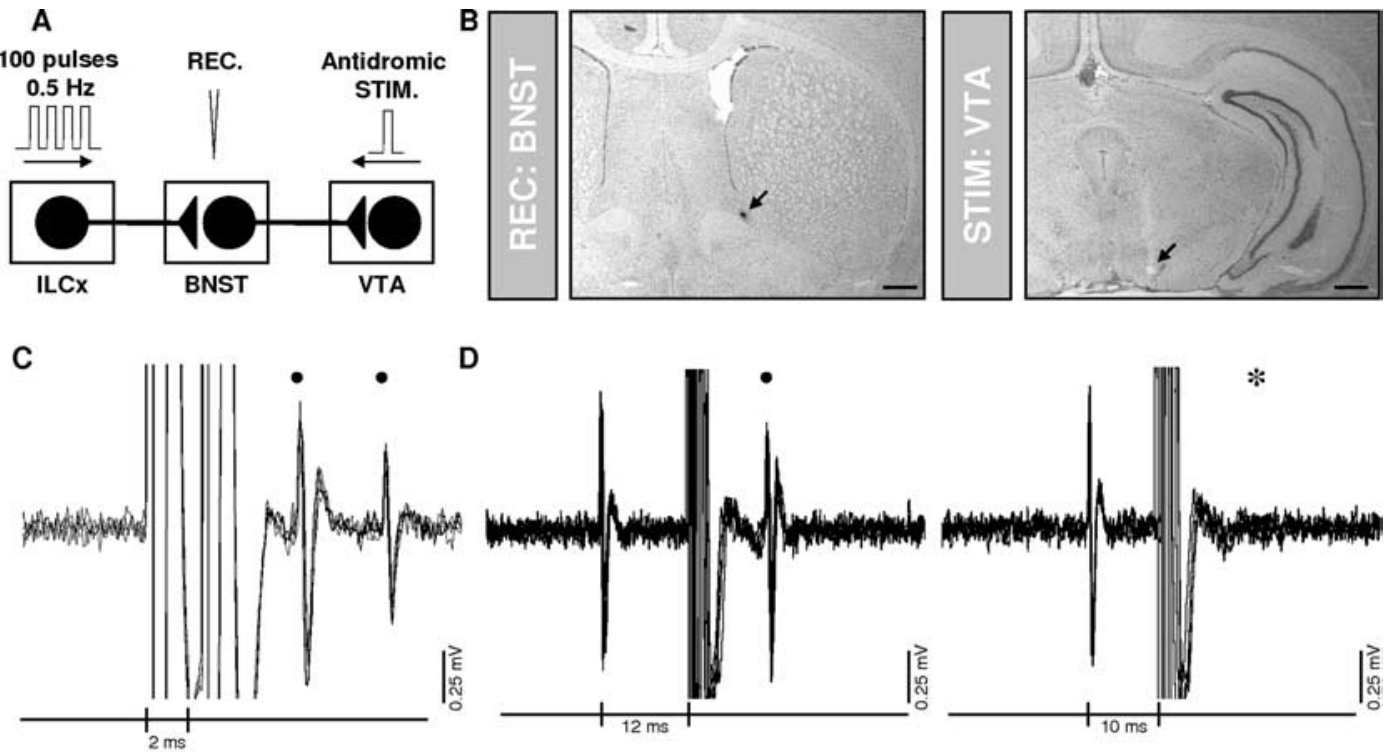

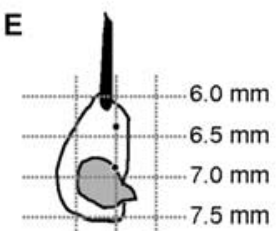

$101.52 .0 \mathrm{~mm}$

Bregma: + $0.2 \mathrm{~mm}$

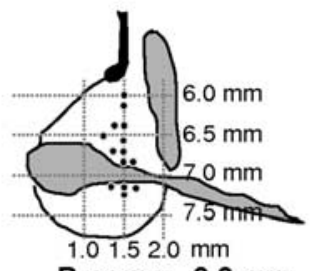

Bregma: $0.0 \mathrm{~mm}$

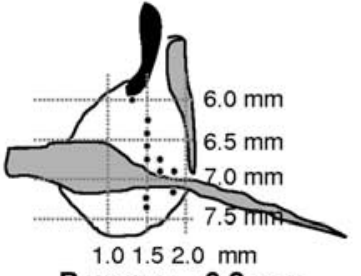

Bregma: $-0.2 \mathrm{~mm}$

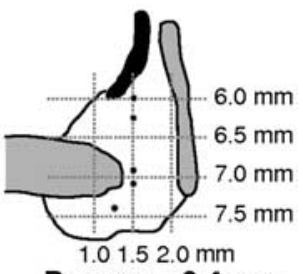

Bregma: $-0.4 \mathrm{~mm}$

$\mathbf{F}$
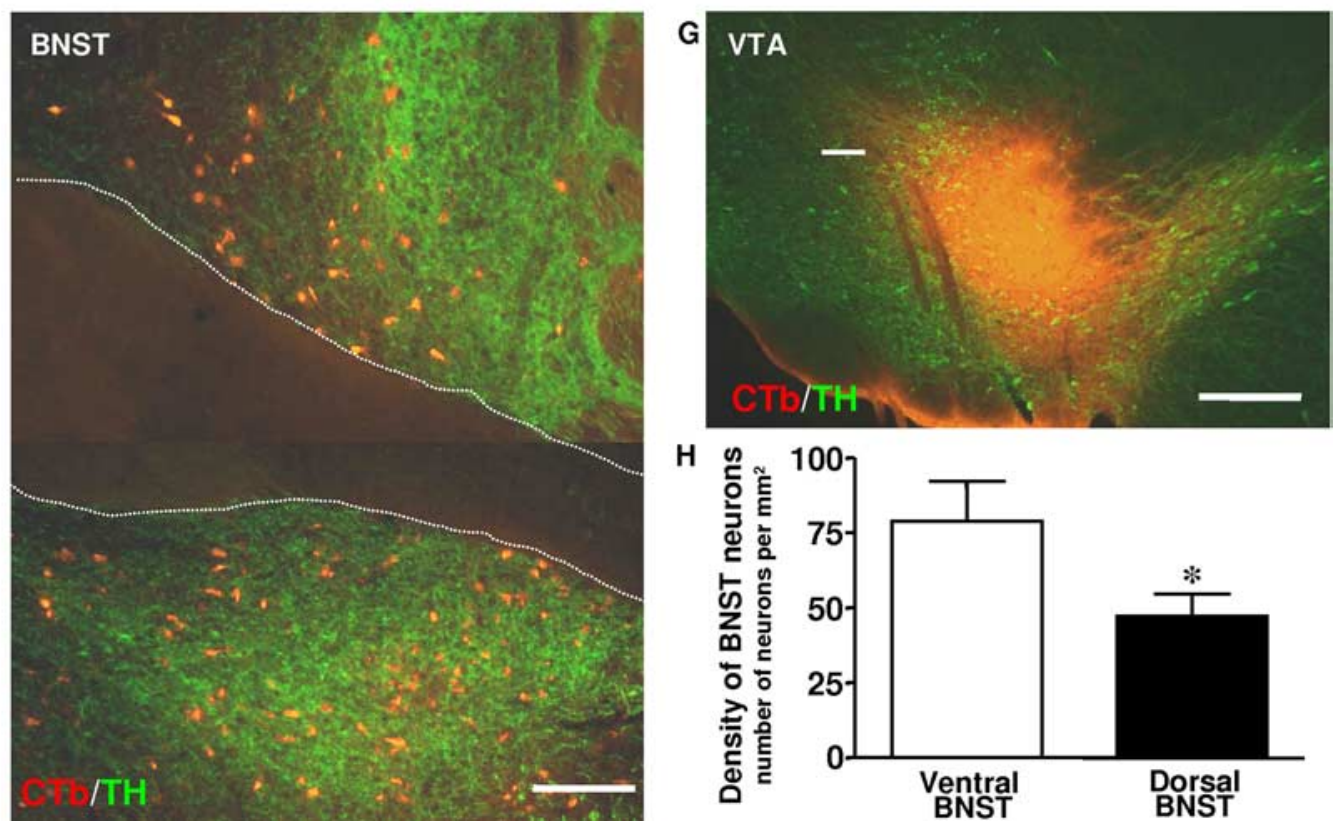

$\mathrm{H}$

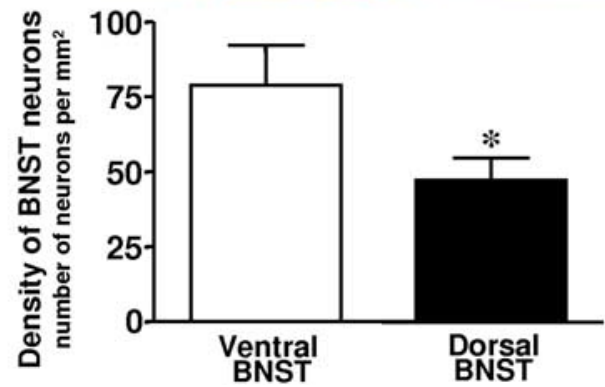

Figure 1. Projection from the BNST to the VTA revealed by antidromic stimulation from the VTA and retrograde labeling in the BNST after injection of CTb into the VTA. $\boldsymbol{A}$, Diagram of the stimulation protocol used in this experiment. Here, the IL was stimulated with a 100-pulse train, and BNST neurons projecting to the VTA were identified by antidromic activation from the VTA. $\boldsymbol{B}$, Left, Recording location for a BNST neuron projecting to the VTA (dark spot, black arrow). Right, Electrical stimulation site in the VTA (lesioned area, black arrow). Scale bars, 0.5 mm. $\boldsymbol{C}, \boldsymbol{D}$, Five superimposed traces illustrating high-frequency activation and collision test for a BNST cell driven from the VTA. C, Driven spikes (black circles) elicited by each paired stimuli (vertical lines, 2 ms interpulse interval), indicating frequency following for this cell at $500 \mathrm{~Hz}$. D, Left, Stimulation of the VTA 12 ms after spontaneous spikes (left side of traces) elicit driven spikes (black circle) at 9.5 ms latency. Right, Driven spikes are occluded for similar stimuli delivered $10 \mathrm{~ms}$ after spontaneous impulses indicating collision between spontaneous and driven spikes. The asterisk indicates when driven spikes would have occurred had there been no collision. $\boldsymbol{E}$, Schematic presentation of neuronal recording sites in the BNST of neurons projecting to the VTA. Black circles, Locations of synaptically driven BNST neurons by single-pulse ILCx electrical stimulation. Numbers refer to stereotaxic coordinates. Note that all of the BNST neurons projecting to the VTA tested were driven by ILCx stimulation. $\boldsymbol{F}-\boldsymbol{H}$, Projection from the BNST to the VTA revealed by retrograde labeling in the BNST after injection of CTb into the VTA. $\boldsymbol{F}$, Epifluorescence photomicrographs illustrating retrograde labeling in the dorsal and ventral parts of the BNST after CTb injection into the VTA. G, Photomicrograph illustrating a representative CTb injection site in the VTA. The sections have been processed dually for (Tb (red) and TH (green). Scale bars: $\boldsymbol{F}, 100 \mu \mathrm{m} ; \boldsymbol{G}, 200 \mu \mathrm{m}$. $\boldsymbol{H}$, Bar histograms comparing the density of (Tb-immunoreactive neurons in the dorsal and ventral BNST after an injection of CTb in the VTA ( $n=15$ rats perfused $7 \mathrm{~d}$ after receiving (Tb into the VTA). $t$ test was used to establish statistical differences between the dorsal and the ventral part of the BNST. ${ }^{*} p<0.05$, Student's $t$ test. REC, Recording electrode; STIM, stimulation. 

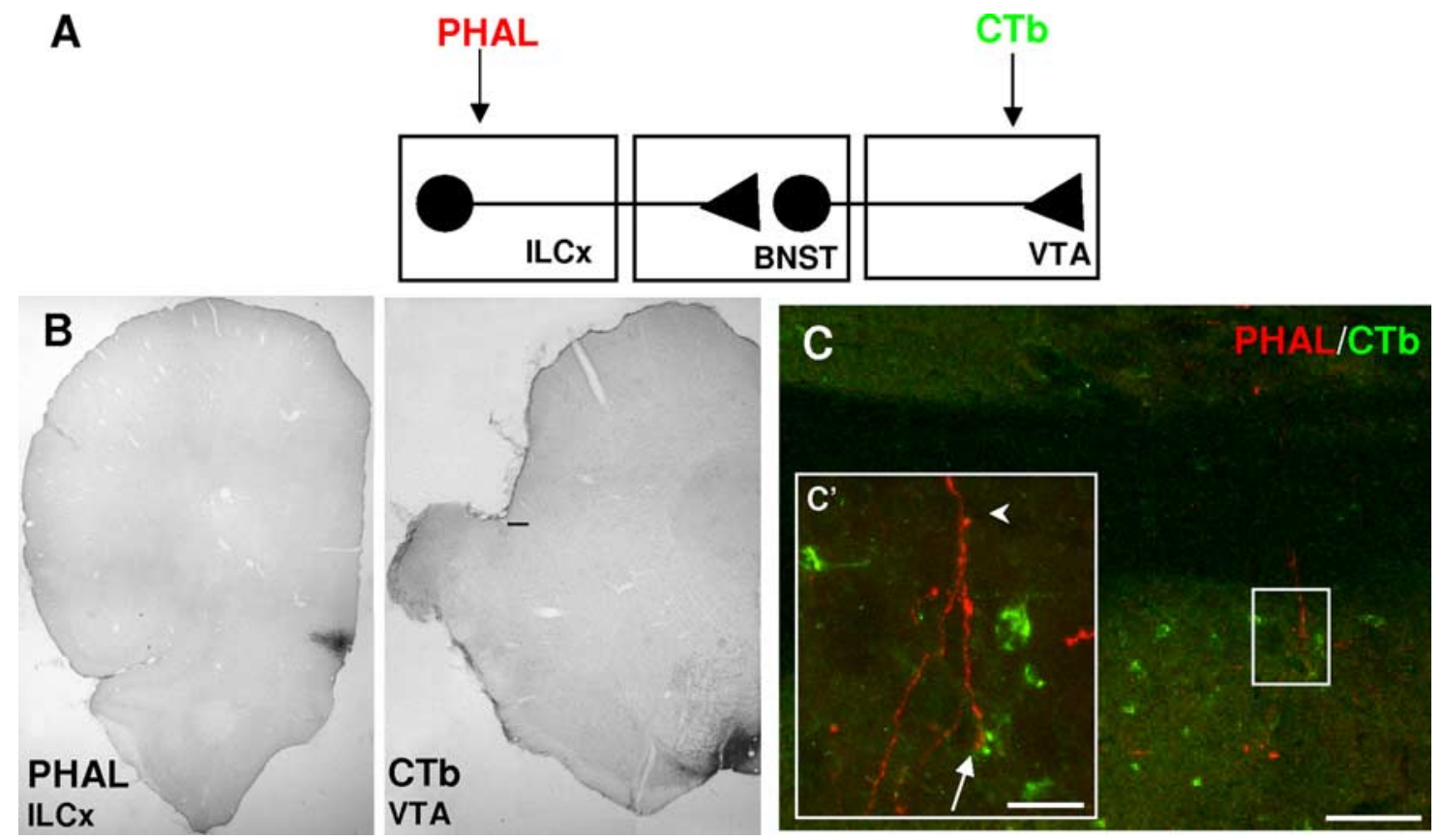

Figure 2. Detection of PHA-L and CTb in the BNST after injection in the prefrontal cortex and mesencephalon (diagram in $\boldsymbol{A}$ ). $\boldsymbol{B}$, Injection sites. Left, The anterograde tracer PHA-L was injected in the infralimbic cortex (ILCX): bregma $+3.0 \mathrm{~mm} ; 0.5 \mathrm{~mm}$ from medial line and $4.5 \mathrm{~mm}$ from surface. Right, The retrograde tracer CTb was restricted to the VTA: bregma, $-5.3 \mathrm{~mm} ; 0.8 \mathrm{~mm}$ from medial line and $8.2 \mathrm{~mm}$ from surface. Scale bar, $100 \mu \mathrm{m}$. C, Immunofluorescence confocal image showing the ILCx projection to the BNST. $\boldsymbol{C}^{\prime}$, Note how some PHA-L positive axons (arrowhead) reach the neuropile and cell bodies of CTb-positive neurons (arrow). Scale bars: $\boldsymbol{C}, 100 \mu \mathrm{m} ; \boldsymbol{C}^{\prime}, 20 \mu \mathrm{m}$.

body weight. Concentrations of these solutions were set so that injection volumes would range between 0.2 and $0.30 \mathrm{ml}$. The doses of these drugs were chosen from previous studies (Georges and Aston-Jones, 2002).

Tract-tracing method. Tracer injections were performed as described previously (Georges and Aston-Jones, 2002) with the following modifications. For retrograde tracing, $20 \mathrm{~nL}$ of $0.5 \%$ cholera toxin subunit $\mathrm{B}$ (CTb) (List Biological Laboratories) were microinfused by pressure, in the VTA $(n=4)$ or in the BNST $(n=4)$ (supplemental Fig. 1, available at www.jneurosci.org as supplemental material). For PHA-L tracing, the skull was exposed, and a hole was drilled above the ILCX $(n=4)$. Animals received a single iontophoretic injection of a $2.5 \%$ solution of PHA-L (Vector Laboratories), prepared in $0.1 \mathrm{~m}$ sodium PBS, pH 7.4, into ILCx $(n=4)$ through a glass micropipette ( $15 \mu \mathrm{m}$ tip diameter) by applying a positive current ( $20 \mu \mathrm{A}, 2 \mathrm{~s}$ on/off intervals) for 25-30 min. Animals were allowed to survive $7-10 \mathrm{~d}$.

Immunohistochemical methods. Immunocytochemical detection was performed by standard light, confocal, or electron microscopy as described previously (Georges and Aston-Jones, 2002; Lafourcade et al., 2007). Rats injected with retrograde and anterograde tracers were deeply anesthetized with chloral hydrate $(400 \mathrm{mg} / \mathrm{kg}$ body weight). The animals were transcardially perfused with PBS $(0.1 \mathrm{M} ; \mathrm{pH} 7.4)$ and then fixed by $500 \mathrm{ml}$ of a fixative made up of $0.025 \%$ glutaraldehyde, $4 \%$ formaldehyde (freshly depolymerized from paraformaldehyde), and $0.2 \%$ picric acid in PBS. Perfusates were used at $4^{\circ} \mathrm{C}$. Tissue blocks were extensively rinsed in $0.1 \mathrm{~m}$ PBS, pH 7.4. Coronal BNST vibrosections were cut at $50 \mu \mathrm{m}$ and collected in $0.1 \mathrm{~m} \mathrm{PBS}, \mathrm{pH} 7.4$, at room temperature (RT).

For epifluorescent and confocal microscopy, tissue was preincubated with $3 \%$ bovine serum albumin (BSA)/PBS containing $0.5 \%$ Triton $\mathrm{X}-100$ for $1 \mathrm{~h}$. Primary polyclonal goat anti-CTb (1:20,000; List Biological Laboratories), rabbit anti-PHA-L (1:2000; Vector Laboratories), rabbit antityrosine hydroxylase (TH; 1:10,000; Institut Jacques Boy), and guinea pig anti-CB1-R ( $3 \mu \mathrm{g} / \mathrm{ml}$; generously provided by Prof. Dr. Masahiko Watanabe, Department of Anatomy, Hokkaido University School of Medicine, Sapporo, Japan) antibodies were diluted in 1.5\% BSA/PBS. $\mathrm{CTb}$ immunofluorescence was detected by $\mathrm{Cy} 3$ or Alexa Fluor- 488 conjugated donkey anti-goat antibodies (1:800 in 1.5\% BSA/PBS; Jackson ImmunoResearch Laboratories and Invitrogen, respectively), whereas TH antibodies were visualized by an Alexa Fluor-488 donkey anti-rabbit antibody (1:800 in 1.5\% BSA/PBS; Jackson ImmunoResearch Laboratories). The rabbit anti-PHA-L and the guinea pig anti-CB1-R antibodies were localized with Alexa Fluor-594 donkey anti-rabbit and Alexa Fluor488 goat anti-guinea pig antibodies, respectively (1:800 in 1.5\% BSA/ PBS; Invitrogen). Incubations with the secondary fluorescent antibodies were stored overnight at $4^{\circ} \mathrm{C}$. Tissue sections were washed in $0.1 \mathrm{~m} \mathrm{PBS}$ and then mounted in Vectashield medium (Vector Laboratories), coverslipped, and imaged on a laser-scanning confocal microscope (Fluoview FV500; Olympus). Photomicrographs were taken and displayed using Adobe Photoshop 7 (Adobe Systems).

$C B 1 R$ immunocytochemistry for electron microscopy. The study of CB1-R relies on the availability of highly specific antibodies (Grimsey et al., 2008). Thus, $C B 1 \mathrm{R}^{-1-}$ knock-out mice were used for control of antibody specificity $(n=2$; kindly provided by Dr. Giovanni Marsicano, Institute François Magendie, Bordeaux, France) (Marsicano et al., 2002). Mice were deeply anesthetized by intraperitoneal injection of a mixture of Nembutal (5 mg/100 g body weight; Abbott Laboratories) and urethane $(130 \mathrm{mg} / 100 \mathrm{~g}$ body weight; Sigma-Aldrich). In addition, rats injected with tracers were deeply anesthetized as above.

All animals were transcardially perfused with PBS (0.1 M; pH 7.4) and then fixed by $500 \mathrm{ml}$ of a fixative made up of $0.1 \%$ glutaraldehyde, $4 \%$ formaldehyde, and $0.2 \%$ picric acid in PBS. Perfusates were used at $4^{\circ} \mathrm{C}$. Tissue blocks were extensively rinsed in $0.1 \mathrm{M}$ PBS, pH 7.4. Coronal 50 $\mu \mathrm{m}$-thick BNST vibrosections were collected in $0.1 \mathrm{M}$ PBS, pH 7.4, at RT. The immunolocalization of CB1-R in $\mathrm{CB} 1 \mathrm{R}^{-/-}$knock-out and wildtype mice was by a preembedding immunogold method described below.

For CTb/CB1-R or PHA-L/CB1-R, floating sections were preincubated in 20\% BSA/PBS for $1 \mathrm{~h}$ at RT and incubated with rabbit PHA-L (1:2000 in 1.5\% BSA/PBS; Vector Laboratories) or goat CTb polyclonal antibodies (1:20,000 in 1.5\% BSA/PBS; List Biological Laboratories) for $3 \mathrm{~d}$ at $4^{\circ} \mathrm{C}$. Also, each antibody was incubated with polyclonal guinea pig anti-CB1-R antibodies ( $3 \mu \mathrm{g} / \mathrm{ml}$ in $1.5 \%$ BSA/PBS; generously gifted by Prof. Dr. Masahiko Watanabe, Department of Anatomy, Hokkaido University School of Medicine, Sapporo, Japan) for $3 \mathrm{~d}$ at $4^{\circ} \mathrm{C}$. The immunolocalization of PHA-L/CB1-R and CTb/CB1-R was performed by a preembedding immunogold and an immunoperoxidase method, being CB1-R revealed by a $1.4 \mathrm{~nm}$ gold-labeled goat anti-guinea pig IgG (Fab fragment; $1: 100$ in 1.5\% BSA/PBS; Nanoprobes), PHA-L by a biotinyl- 
ated goat anti-rabbit, and CTb by a biotinylated donkey anti-goat IgG (1:200 in 1.5\% BSA/PBS; Jackson ImmunoResearch Laboratories).

BNST tissue was washed in PBS and processed by a conventional avidin-biotin horseradish peroxidase complex method (ABC; Elite; Vector Laboratories). Tissue was washed in PBS overnight at $4^{\circ} \mathrm{C}$ and postfixed in $1 \%$ glutaraldehyde in PBS for 10 min at RT. After washes in double-distilled water, gold particles were silver-intensified with a HQ Silver kit (Nanoprobes) for $\sim 12 \mathrm{~min}$ in the dark and then washed in $0.1 \mathrm{M} \mathrm{PB}, \mathrm{pH}$ 7.4. Sections were preincubated subsequently with $0.05 \% \mathrm{DAB}$ in 0.1 M PB for $5 \mathrm{~min}$, incubated by adding $0.01 \%$ hydrogen peroxide to the same solution for 5 min, and washed overnight in $0.1 \mathrm{M} \mathrm{PB}$ at $4^{\circ} \mathrm{C}$. The following day, tissue sections were osmicated, dehydrated, and embedded in Epon 812 resin. Ultrathin sections $(80 \mathrm{~nm})$ were collected on mesh nickel grids, stained with lead citrate, and examined using a JEOL X-100 transmission electron microscope. Preparations were photographed by using standard electron microscopy negative plates. Figure compositions were scanned at 300 dots per inch. Labeling and minor adjustments in contrast and brightness were made using Adobe Photoshop 7 (Adobe Systems).

Data analysis. For in vivo electrophysiological experiments, cumulative peristimulus time histograms (PSTHs; $5 \mathrm{~ms}$ bin width) of BNST activity were generated during electrical stimulation of the ILCx, for each neuron recorded. PSTHs were analyzed to determine excitatory and inhibitory epochs (Georges and Aston-Jones, 2002). In brief, the mean and SD of counts per bin were determined for a baseline period, defined as the $500 \mathrm{~ms}$ epoch preceding stimulation. The onset of excitation was defined as the first of five bins whose mean value exceeded mean baseline activity by $2 \mathrm{SD}$, and response offset was determined as the time at which activity had returned to be consistently within 2 SD of baseline. Excitatory response magnitudes were normalized for different levels of baseline impulse activity, allowing comparison of drug effects on evoked responses independent of effects on baseline activity. Response magnitudes for excitation were calculated with the following equation: (counts in excitatory epoch $)-($ mean counts per baseline bin $\times$ number of bins in excitatory epoch). Response magnitude for inhibition was calculated by comparing the number of bins in inhibitory epoch before and after drug treatments. For VTA DA neurons, two parameters of impulse activity were computed $>200$ s epochs before and after drug administration: the basal firing rate and the proportion of spikes that occurred in bursts. The onset of a burst was defined as the occurrence of two spikes with an interspike interval $<80 \mathrm{~ms}$. The percentage of spikes in bursts (SIB) was calculated by dividing the number of spikes occurring in bursts by the total number of spikes occurring in the same period of time. Variations of burst firing are reported throughout this study as the percentage of SIB postdrug minus the percentage of SIB predrug. Results are expressed as mean \pm SEM. These values were subjected to a one-way ANOVA followed by post hoc Newmans-Keuls test or Dunnett's test. When two means were compared, statistical significance of their difference was assessed using two-tailed paired Student's $t$ tests. For immunochemistry experiments, BNST sections from eight rats were analyzed. Electron micrographs were taken at a final magnification of $15,000 \times$ from $150 \mu \mathrm{m}$ grid squares showing good and reproducible DAB immunoreactions and silver-intensified gold particles for any condition studied. ImageJ (version 1.36) was used to measure the membrane length. Positive labeling was considered if immunoparticles were in close proximity to the plasmalemma. Metal particles on membranes and positive immunoreactive profiles were visualized and counted manually. The total area studied for CB1-R was $\approx 1115.99 \mu \mathrm{m}^{2}$, PHA-L $\approx 1532.01 \mu \mathrm{m}^{2}, \mathrm{CTb} \approx 1033.32$ $\mu \mathrm{m}^{2}$. The densities of immunoparticles were averaged from different samples and presented as the mean \pm SEM.

\section{Results}

Compared with other components of the ExtA, few studies have examined the electrophysical properties of BNST neurons (Rainnie, 1999; Egli and Winder, 2003; Dumont and Williams, 2004; Hammack et al., 2007). The in vivo properties of BNST neurons and their putative regulation by cannabinoids had never been reported. Here, we examined in vivo the electrophysiological properties of BNST neurons and their control by the prefrontal cortex. Extracellular recordings from a total of 207 neurons histologically identified as being within the BNST, were obtained from rats $(n=92)$ in which the stimulating electrode was in the ILCx (Table 1) (supplemental Fig. 2, available at www.jneurosci.org as supplemental material). Injections of the retrograde tracer CTb into the BNST (supplemental Fig. 1, available at www.jneurosci.org as supplemental material) showed that cortical projections to the BNST originate exclusively from the ILCx. In each of the four animals injected with $\mathrm{CTb}$, we observed numerous retrogradely labeled neurons in the ILCx (supplemental Fig. 1 , available at www.jneurosci.org as supplemental material). No anterograde labeling was detected in the ILCx. These data show that among prefrontal cortices, the ILCx has prevalent projections to the BNST.

\section{BNST neurons that project to the VTA receive potent projections from the infralimbic cortex}

The BNST is a heterogeneous cell group with multiple efferent projections. There are no clear cytoarchitectural boundaries differentiating subaspects of the BNST. However, the BNST is well defined by a dense noradrenergic and dopaminergic innervation (Delfs et al., 2000; Healey et al., 2008). Thus, we examined projection from the BNST to the VTA using tract-tracing approach and by immunohistochemical staining for TH to reveal dopaminergic and noradrenergic fibers (Fig. 1). We made microinjections of $\mathrm{CTb}$, a sensitive retrograde tracer into the VTA and analyzed tissue for retrogradely labeled neurons. In each of 15 animals with CTb injections in the VTA, we observed a higher proportion of retrogradely labeled cell bodies in the ventral BNST $(62 \%)$ compared with the dorsal $(38 \%$; $t$ test, $p<0.05)$ (Fig. $1 H)$. Given that neurons in the BNST send an excitatory projection to the VTA (Georges and Aston-Jones, 2002), we focused on iden- 
tified BNST neurons innervating VTA DA neurons. The general electrophysiological properties of BNST neurons are summarized in Table 1. For each BNST neuron studied, electrical connectivity to the midbrain was tested by antidromic activation from the VTA (Georges and Aston-Jones, 2002): 15.4\% of BNST neurons (32 of 207) were antidromically driven from the VTA (Fig. $1 A-D$ ). BNST neurons projecting to the VTA had mean antidromic latencies of $10.1 \pm 0.5 \mathrm{~ms}$ and shared physiological properties with the general population (Table 1). Electrical stimulation of the ILCx region showed similar effectiveness in driving BNST neurons projecting to the VTA and BNST neurons projecting elsewhere (supplemental Fig. 3, available at www. jneurosci.org as supplemental material). Antidromicity was determined by collision tests and by response to high-frequency stimulation (Fig. $1 B-D$ ). The majority of this subpopulation of BNST neurons was silent or nearly so (18 of 32). The spontaneously active BNST neurons (14 of 32) typically fired in an irregular pattern and their action potentials were biphasic or triphasic. Electrical stimulation of the ILCx region proved more effective in driving BNST neurons projecting to the VTA than either prelimbic (PLCx) or cingular cortex (CgCx) (supplemental Fig. 1, available at www.jneurosci.org as supplemental material) $\left(F_{(2,11)}=\right.$ 30.95; $p<0.001)$. Within these 32 BNST neurons projecting to the VTA, 22 responded to ILCx stimulation with an orthodromic-evoked excitation (onset latency, $9.4 \pm 0.7 \mathrm{~ms}$; duration, $10.5 \pm 1.0 \mathrm{~ms}$ ), 4 with an evoked inhibition (onset latency, $10.9 \pm 3.3 \mathrm{~ms}$; duration, $85.0 \pm 29.7 \mathrm{~ms}$ ), and 6 with an evoked excitation followed by an inhibition. Quantified data are summarized in Table 1.

A double-labeling strategy combining injection of the anterograde tracer PHA-L in the ILCx and injection of CTb in the VTA confirmed that cortical projections arising from the infralimbic cortex converge on BNST neurons, which in turn project to VTA (Fig. 2). The greatest density of CTb-labeled neurons was found in the anteromedial portion of the BNST, coincident with the PHA-L-cortical labeling that originated from the ILCx. Our data show that ILCx exerts a phasic excitatory influence over the firing characteristics of BNST neurons projecting to the VTA and provide the first anatomical and functional evidence that the BNST relays the excitatory drive from the ILCx to the midbrain DA neurons (Fig. 2, Table 1; supplemental Fig. 3, available at www. jneurosci.org as supplemental material).

\section{AMPA and NMDA glutamate receptors in the BNST mediate the excitatory responses from ILCx}

Excitatory synaptic inputs are a key component of the regulation of BNST cell excitability (Dumont and Williams, 2004; Egli et al., 2005). In ex vivo slice experiments, EPSPs evoked in the BNST contain both an AMPA and NMDA receptor-mediated component (Egli et al., 2005). Therefore, we tested whether these receptors mediate the excitatory response on BNST neurons evoked by ILCx stimulation. Microinfusion of a mixture of AP5 (NMDA antagonist, $100 \mu \mathrm{M}$ ) and CNQX (non-NMDA antagonist, $50 \mu \mathrm{M}$ ) into the BNST abolished the short latency excitation evoked by ILCx stimulation (Fig. 3D) (ANOVA; $F_{(2,17)}=39.46 ; p<$ $0.0001)$. A characteristic cell that projected to the VTA is shown in Figure 3C. Partial or full recovery had occurred for most cells 15 min after microinjection. The AP5 plus CNQX mixture had no effect on the inhibitory response (Fig. $3 E$ ). Notably, baseline firing rates of BNST neurons decreased by $88 \%$ during microinjection of AP5 plus CNQX (Fig. $3 F)\left(F_{(2,27)}=19.10 ; p<0.0001\right)$. However, as our method of calculating response magnitude nor- malized for different baseline rates, the decreased baseline activity does not account for the decreased evoked response from ILCx.

\section{$\mathrm{GABA}_{\mathrm{A}}$ antagonist releases an inhibitory drive on the excitatory responses from ILCx}

To gauge the contribution of the GABAergic system on the BNST neuron responses evoked by ILCx stimulation, we performed extracellular recordings in the presence of the $\mathrm{GABA}_{\mathrm{A}}$ receptor antagonist picrotoxin. Microinfusion of picrotoxin (1 mM) increased the short latency excitation evoked by ILCx stimulation (Fig. 3D) (ANOVA; $\left.F_{(2,17)}=39.46 ; p<0.01\right)$. A typical response showing the dramatic enhancement of the response probability after ILCx stimulation in a characteristic cell that projected to the VTA is shown Figure $3 B$. In contrast, microinfusion of picrotoxin into the BNST did not affect the inhibitory response evoked in BNST by ILCx stimulation (Fig. 3E) (ANOVA; $F_{(2,20)}=1.714$; $p=0.233)$. Picrotoxin did not affect baseline firing rates of BNST neurons (Fig. $3 F)(p>0.05)$. These data show that the $\mathrm{GABA}_{\mathrm{A}}$ receptor in the BNST drives a phasic inhibitory influence over the spiking probability of BNST neurons evoked by ILCx stimulation. However, our findings suggest that there is not a high level of spontaneous GABA release that contributes to tonic regulation of BNST neurons activity, consistent with the absence of effect of picrotoxin on basal firing activity. Our data show that the ILCX exerts a powerful phasic control over the activity of BNST neurons via ionotropic glutamate receptors (NMDA and AMPA/ kainate), and this response is further modulated by $\mathrm{GABA}_{\mathrm{A}}$ receptor activity. NMDA and AMPA/kainate receptor antagonists dramatically decreased basal-steady state activity suggesting a stimulatory tonic influence of glutamatergic synapses within the BNST.

\section{The BNST relays the excitatory drive from the ILCx to DA neurons}

Although there is only a weak direct projection from the ILCx to the VTA (Geisler et al., 2007), there are several potential pathways via which the ILCx could affect DA neuron firing. For instance, the ILCx projects to the BNST (Vertes, 2004), which provides direct and potent inputs to DA neurons (Georges and AstonJones, 2002). This was assessed by electrical stimulation of the ILCx (Fig. 4A) (100-pulses train, $0.5 \mathrm{~Hz}$ ) and pharmacological inactivation of the excitatory receptors within the BNST (Fig. $4 A$ ). In a separate group of recordings of DA neurons, $86 \%$ of the neurons tested ( $n=41 ; 18$ rats) were activated in response to ILCx stimulation, but showed no monosynaptic response (onset of excitation, $\approx 20 \mathrm{~ms}$ ) (Table 1$)$. Infusion of the AP5 (100 $\mu \mathrm{M})$ plus CNQX $(50 \mu \mathrm{M})$ mixture within the BNST blocked the excitatory drive from the infralimbic cortex on VTA dopaminergic neurons (Fig. $4 B, C)(p<0.001 ; n=7$ rats; 7 neurons) but had no effect on the basal firing rate or bursting activity (Fig. $4 D, E$ ). These data identify the BNST as a relay amplifying the excitatory transmission between the ILCx and midbrain DA neurons, as suggested by the large proportion of VTA DA neurons driven by the stimulation of the ILCx.

\section{Ultrastructural localization of CB1-R within the BNST with respect to projections from the ILCx}

Activity at the CB1-R in the ExtA has been postulated as the basis of autoregulatory mechanisms compensating for excessive activation of postsynaptic neurons by glutamate (Azad et al., 2003; Domenici et al., 2006). We combined tract tracing to confocal and electron microscopy approaches to localize CB1-R within the BNST (Fig. 5). We examined the precise localization of CB1-Rs 
A

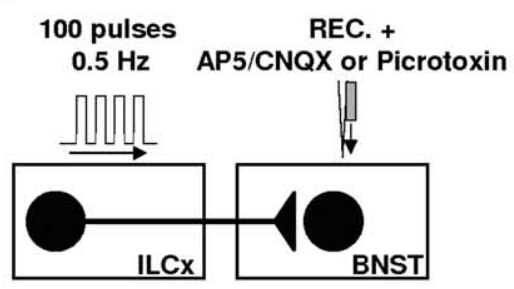

C
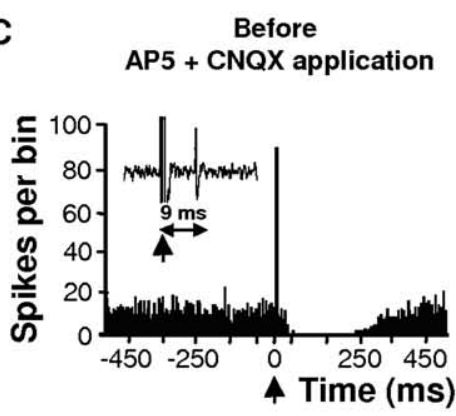

D

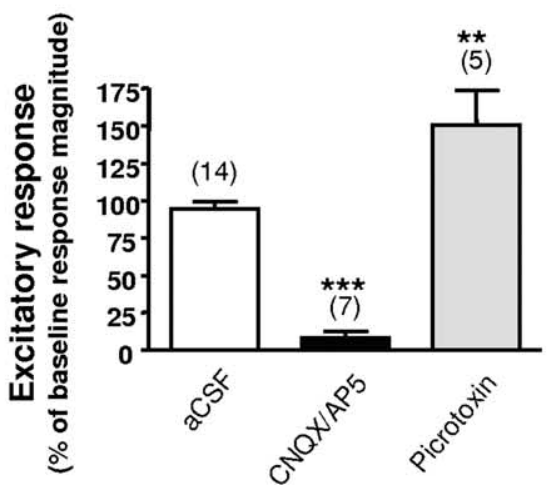

Before picrotoxin application

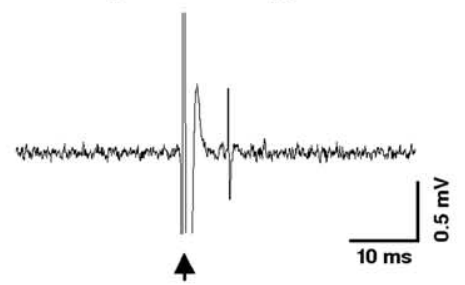

During

AP5 + CNQX application

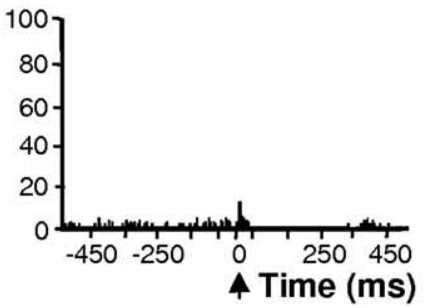

E

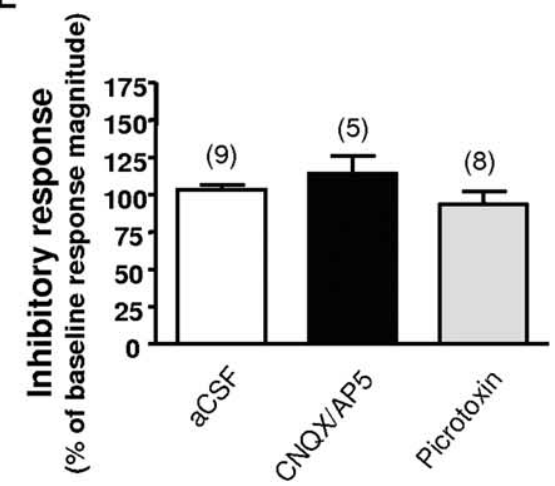

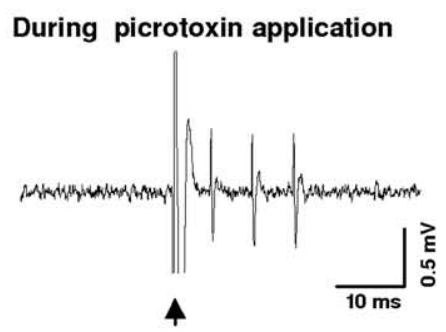

Recovery

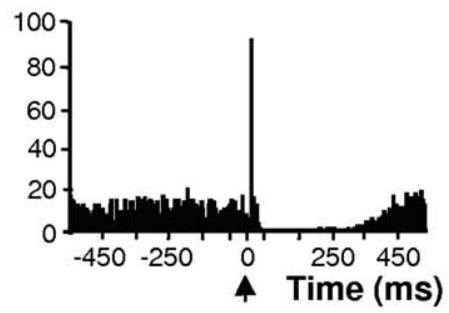

$\mathbf{F}$

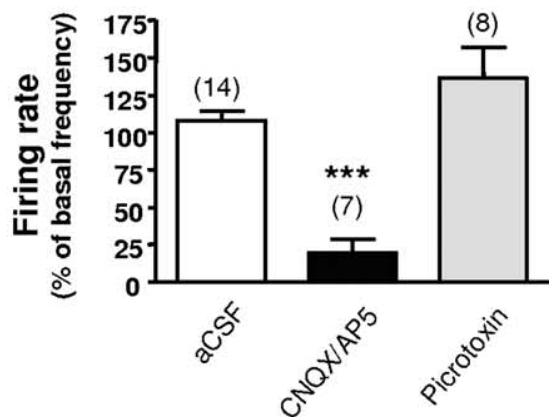

Figure 3. Infusion of glutamatergic receptor antagonists within the BNST block the excitatory drive from the infralimbic cortex on BNST neurons that project to the VTA. $A$, Diagram of the stimulation protocol: ILCX was stimulated with a 100-pulse train. The CNQX plus AP5 mixture or picrotoxin was microinfused through a pipette adjacent to the recording electrode. $\boldsymbol{B}$, Effect of local infusion of picrotoxin (1 mM) on a characteristic BNST neuron projecting to the VTA during ILC electrical stimulation. Representative traces show that picrotoxin enhanced the response probability. C, Effect of the CNQX plus AP5 mixture on a characteristic BNST neuron projecting to the VTA during ILCx electrical stimulation. Typical PSTHs show ILCx-evoked responses before, during, and after (recovery) CNQX plus AP5 injection into the BNST for the same BNST neuron identified as projecting to the VTA. Inset, Orthodromic spikes evoked by stimulation of ILCX. Microinjection of CNQX plus AP5 prevented the short latency activation of BNST neurons evoked by ILCX stimulation, decreased the basal activity, but had no effect on the inhibition. $\boldsymbol{D}-\boldsymbol{F}$, Graphs illustrating the effects of ionotropic glutamatergic (black bars) and GABA-A (gray bars) antagonists on excitation $(\boldsymbol{D})$ and inhibition $(\boldsymbol{E})$ obtained after stimulation of the IL $C$ x and on basal activity $(\boldsymbol{F})$. Scores are percentages \pm SEM of baseline response magnitudes $(\boldsymbol{D}, \boldsymbol{E})$ or basal activity $(\boldsymbol{F})$ for BNST neuronal responses evoked by ILCx electrical stimulation during microinjection into the BNST of aCSF (white bars), the mixture of $50 \mu \mathrm{M}$ CNQX plus $100 \mu \mathrm{m}$ AP5 (black bars), or 1 mm picrotoxin (gray bars). Numbers of neurons recorded in each group are mentioned in parentheses above each histogram bar. An ANOVA followed by Newman-Keuls test for pairwise comparisons was performed for excitation, inhibition, and basal activity. ${ }^{* * *} p<0.001$; ${ }^{* *} p<0.01$. REC, Recording electrode.

with respect to projections from the ILCx. We made iontophoretic injections of $\mathrm{PHA}-\mathrm{L}$, a sensitive anterograde tracer (Delfs et al., 1998), into ILCx and analyzed BNST tissue for anterogradely labeled fibers (Fig. $5 A-D$ ). In each of four animals with PHA-L injections in the ILCx, we observed a large number of anterogradely labeled fibers in the anteromedial part of the BNST. Immunogold method for the CB1-R revealed that PHA-L immunoreactivity frequently colocalized with CB1-R in axon terminals (Fig. 5C,D). CB1-R immunoparticles were absent from the presynaptic specializations of the synapses. CB1-R immunoparticles were not detected in BNST from CB1-R KO mice (a gift from Dr. G. Marsicano, INSERM U862, Bordeaux, France) demonstrating the specificity of the CB1-R antibody. However, some scattered unspecific immunoparticles were occasionally present in postsynaptic compartments and glial lamellae. The level of background labeling along the membrane was determined by measuring immunoparticle density in the mitochondria, taking as a positive labeling immunoparticles within $\sim 30 \mathrm{~nm}$ from the membrane. The background ( 0.09 particles per $\mu \mathrm{m})$ was negligible compared with the density of labeling ( 0.83 particles per $\mu \mathrm{m})$. Subsequently, the density in the mitochondria was subtracted from the density of immunoparticles on axon membranes. No specific staining was detected in sections processed without primary antiserum where it was replaced instead by goat serum (0.069 particles per $\mu \mathrm{m})$.

We also examined projections from the BNST to the VTA by combining tract-tracing methods with confocal and electron microscopy approaches (Fig. $5 E-G$ ). In each of four animals with a $\mathrm{CTb}$ injection in the VTA, we observed numerous CTb-labeled cell bodies throughout the BNST, as confirming our previous report (Georges and Aston-Jones, 2002). Double immunofluorescence for the $\mathrm{CB} 1-\mathrm{R}$ and $\mathrm{CTb}$ showed that $\mathrm{CB} 1-\mathrm{R}$ processes in 
A

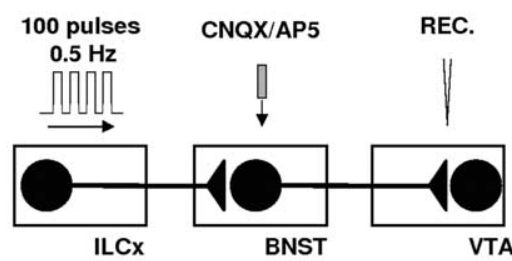

B
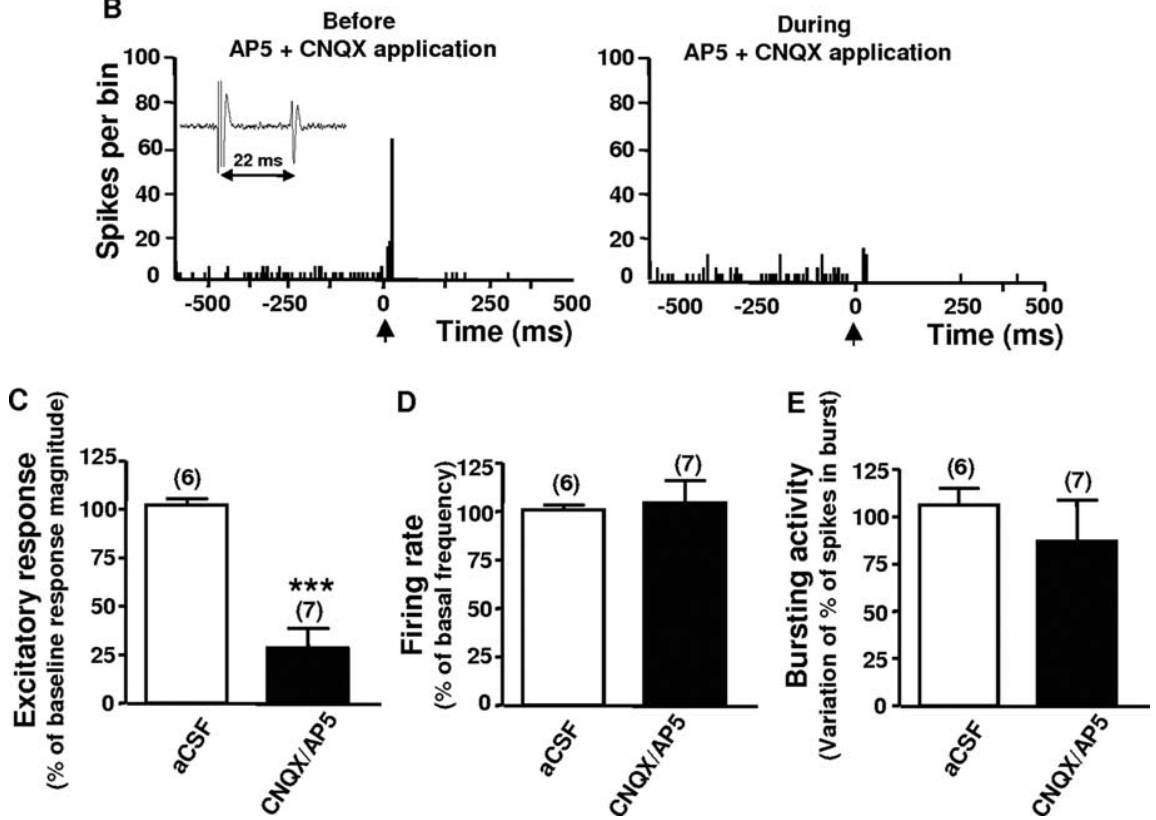

Figure 4. Infusion of glutamatergic receptor antagonists within the BNST blocks the excitatory drive from the infralimbic cortex on VTA dopaminergic neurons. A, Diagram of the stimulation, microinfusion, and recording protocol used in this experiment. Here, the IL was stimulated with a 100-pulse train, and the AP5 (100 $\mu \mathrm{M}$ ) plus CNQX (50 $\mu \mathrm{M})$ mixture was microinfused within the BNST in a total volume of $20-30 \mathrm{nl}>15 \mathrm{~s}$. B. PSTHs showing ILCx-evoked responses in a VTA DA neuron before and during CNQX plus AP5 infusion within the BNST. C $-E$, Graphs illustrating the effects of microinjection of CNQX plus AP5 within the BNST (black bars) on excitation ( $\boldsymbol{C}$ ) obtained after stimulation of the ILC $\mathrm{x}$ and on basal activity parameters $(\boldsymbol{D}, \boldsymbol{E})$. Microinjection of CNQX plus AP5 within the BNST prevented the short latency activation of VTA DA neurons evoked by ILCX stimulation but had no effect on the basal firing rate or bursting activity. Scores are percentages \pm SEM of baseline response magnitudes $(\boldsymbol{C})$ or basal activity parameters $(\boldsymbol{D}, \boldsymbol{E})$ for VTA DA neuronal responses evoked by ILCx electrical stimulation during microinjection into the BNST of aCSF (white bars), or a mixture of $50 \mu \mathrm{m}$ CNQX plus $100 \mu \mathrm{m}$ AP5 (black bars). Numbers of neurons recorded in each group are denoted in parentheses above each histogram bar. A two-tailed paired Student's $t$ test was performed for excitatory responses, firing rate, and bursting activity. ${ }^{* *} p<0.001$. REC, Recording electrode.

the BNST were in close apposition to CTb-positive cell bodies projecting to the VTA (Fig. $5 F$ ). As expected, CTb immunoreactivity was in small dendritic spines (Fig. 5G). Although DAB immunodeposits were diffusely located within the profiles, postsynaptic densities of asymmetrical synapses were observed in CTbpositive spines receiving CB1-R-immunolabeled terminals. However, the CB1-R silver-intensified gold particles were associated with membranes distant from presynaptic specializations of the axon terminals. Quantified data are summarized in Table 2.

\section{Cannabinoids acting at the presynaptic CB1-R inhibits} glutamatergic transmission from the ILCx in the BNST The presence of CB1-R immunolabeling at the axon terminals issued from the ILCx of (presumably glutamatergic) asymmetrical synapses prompted us to test in vivo the effect of cannabinoid agonists at the glutamatergic synapses between ILCx and BNST neurons. To study the pharmacological effect of CB1-R activation on excitatory synaptic transmission, we performed in vivo extracellular recordings of BNST neurons identified as projecting to the VTA. Microinfusion of the cannabinoid receptors agonist WIN 55, 212-2 (WIN; $500 \mu \mathrm{M} ; 30 \mathrm{nl}$ ) into the BNST inhibited the short latency excitation evoked by ILCx stimulation (Fig. 6) $\left(\right.$ ANOVA; $F_{(3,27)}=5.827 ; p<$ 0.01). Intravenous injection of the CB1-R antagonist SR141617A (SR; $1 \mathrm{mg} / \mathrm{kg}$ ) reversed this inhibition. Notably, baseline firing rates of BNST neurons decreased by $46 \%$ during microinjection of WIN 55212-2 (Fig. 6E) (ANOVA; $F_{(3,27)}=$ $6.818 ; p<0.01)$. These data show that CB1-R activation within the BNST potently inhibits the excitatory drive from the ILCx. Moreover, the finding that SR 141617A per se failed to modify the basal electrical activity of BNST neurons suggests that endogenous cannabinoids do not tonically stimulate action on these neurons.

Activation of cannabinoid receptors within the BNST inhibits the excitatory drive from the ILCx to DA neurons

We next tested how CB1-R within the BNST influence the excitatory response of VTA DA neurons evoked by ILCx stimulation. In a separate group of recordings of DA neurons, $86 \%$ of the neurons tested ( $n=35 ; 18$ rats) fired in response to ILCx stimulation, but showed no monosynaptic response (onset of excitation $>19 \mathrm{~ms}$ ) (Table 1). The role of cannabinoid receptors within the BNST on DA neuronal activity evoked by ILCX stimulation was assessed by electrical stimulation of the ILCX (Fig. 7A) (100-pulses train, $0.5 \mathrm{~Hz}$ ) and intra-BNST infusion of the cannabinoid agonist. Microinfusion of WIN 55212-2 $(500 \mu \mathrm{M} ; 100 \mathrm{nl})$ within the BNST inhibited the excitatory drive from the ILCX on VTA DA neurons (Fig. 7C) $(p<0.001$; $n=5$ rats; 5 neurons) but had no effect on the basal firing rate or bursting activity of these DA cells (Fig. $7 D, E)$. The data show that activation of CB1-Rs within the BNST modulates the response of VTA DA neurons to ILCx activity.

\section{Discussion}

The major finding of the present study is that the ILCx efficiently controls DA neurons in the VTA, via glutamatergic synapses localized within the BNST (Fig. 8). Cannabinoids have recently been revealed to mediate presynaptic inhibition of glutamate release within the ExtA (Marsicano et al., 2002), although their role in the BNST remains elusive. Here, we provide evidence that CB1-R modulates synaptic excitation in BNST neurons that directly project to the VTA. Together, the data provide a mechanism underlying cannabinoids' effects on the activity of VTA DA cells.

\section{Glutamatergic transmission in the BNST}

Glutamatergic synapses in the ExtA are involved in stress-related behaviors (Choi et al., 2007) and the effects of addictive drugs (for 
A
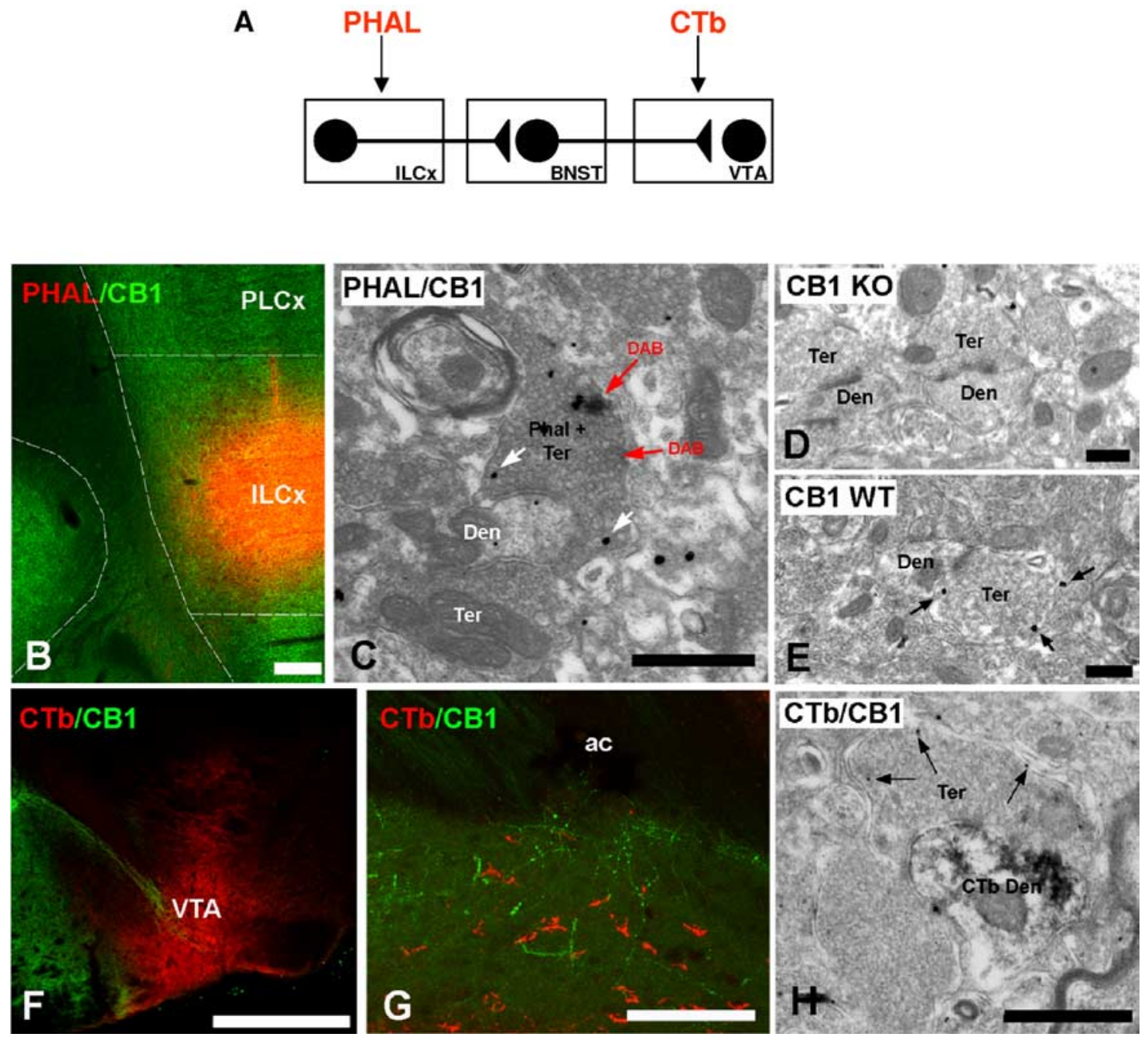

Figure 5. Immunolocalization of CB1-R in the BNST after injection of tracers in the prefrontal cortex (PHA-L) and mesencephalon (CTb; scheme in A). B, Double immunofluorescence confocal for the injection site of the tracer PHA-L (red) injected in the ILCX (scheme on top of the figure) and the expression of CB1-R (green). Scale bar, $500 \mu \mathrm{m}$. C, Electron micrograph showing colocalization of transported PHA-L and immunoreactivity for CB1-Rin terminals in BNST using preembedding immunoperoxidase and immunogold methods, respectively. Cortical axons identified by cytoplasmic DAB deposits (PHA-L plus Ter, red arrow) have CB1-R immunoparticles on their membranes (white arrows). Scale bar, $0.3 \mu \mathrm{m}$. D, E, CB1-R deficient mice (CB1 K0) were used for control of antibody specificity. CB1-R immunolabeling was not observed in the BNST of CB1 K0. In wild-type mice (CB1 WT), CB1-R silver-intensified gold particles were localized along membranes of presynaptic bouton. Scale bar, $0.4 \mu \mathrm{m}$. $\boldsymbol{F}$, Injection site of the retrograde tracer (Tb was restricted to the VTA. Scale bars, $100 \mu \mathrm{m}$. G, Double immunofluorescence confocal for the tracer CTb (red) injected in the VTA and the expression of CB1-R (green) in BNST. Scale bar, $100 \mu \mathrm{m}$. $\boldsymbol{H}$, Subcellular distribution of CTb and CB1-R in BNST using preembedding immunoperoxidase and immunogold methods, respectively, for electron microscopy. Immunodeposits of the retrogradely transport CTb were on dendrites (Den) of BNST projecting neurons to VTA (CTb plus Den) apposed to a CB1-R immunopositive synaptic terminal (Ter) (arrows, (B1-R gold particles) and making an asymmetrical synapse with a CB1-R immunonegative Ter. Scale bar, $0.3 \mu \mathrm{m}$. ac, Anterior commissure.

Table 2. Percentage of presynaptic and postsynaptic elements immunoreactive for CB1-R in the BNST after injection of the anterograde tracer (PHA-L) in the prefrontal cortex and the retrograde tracer (CTb) in the mesencephalon

\begin{tabular}{llllll}
\hline Tracers & Profile & $\begin{array}{l}\text { Percentage of CB1 } \\
\text { positives profiles }\end{array}$ & $\begin{array}{l}\text { No. of particles per } \\
\mu \mathrm{m} \pm \text { SEM }\end{array}$ & $\begin{array}{l}\text { Total no. } \\
\text { of profiles }\end{array}$ & Percentage of total particles distribution \\
\hline PHA-L & Presynaptic (terminals) & 92.68 & $1.13+0.13$ & 86 & 73.83 (membrane) 26.17 (cytoplasm) \\
CTb & Synaptic contact (terminals \pm dendrites) & 77.15 & $0.74+0.05$ & 83 & 70.74 (membrane) 29.86 (cytoplasm) \\
\hline
\end{tabular}

The percentage of CB1-R-labeled presynaptic and postsynaptic compartments relative to PHA-L and postsynaptic CTb is shown. Note that the vast majority of infralimbic terminals within the BNST have the CB1-R. BNST sections used for counting were obtained from four rats. Electron micrographs were taken at a final magnification of $15,000 \times$.

review, see Koob, 2003). The ventral subiculum and cortical areas provide a prominent, known glutamatergic input into the BNST (Herman and Cullinan, 1997). Using retrograde tract-tracing methods, we found that ILCx strongly innervates the BNST through a direct projection, whereas PLCx and CgCx only projects sparingly to this site (supplemental Fig. 1, available at www.jneurosci.org as supplemental material). Accordingly, anterograde tract-tracing approaches (Vertes, 2004) demonstrated dense ILCx but minimal PLCx projections to the BNST. We also provide the first functional evidence of a strong excitatory input to BNST neurons from the ILCx, whereas activation of the PLCX and $\mathrm{CgCx}$ did not drive BNST neurons (supplemental Fig. 1, available at www.jneurosci.org as supplemental material). Our data are consistent with an analogous series of studies using lesion approaches of the anterior BNST showing that this structure is a key hub for integration of cortical input to regulate 
A
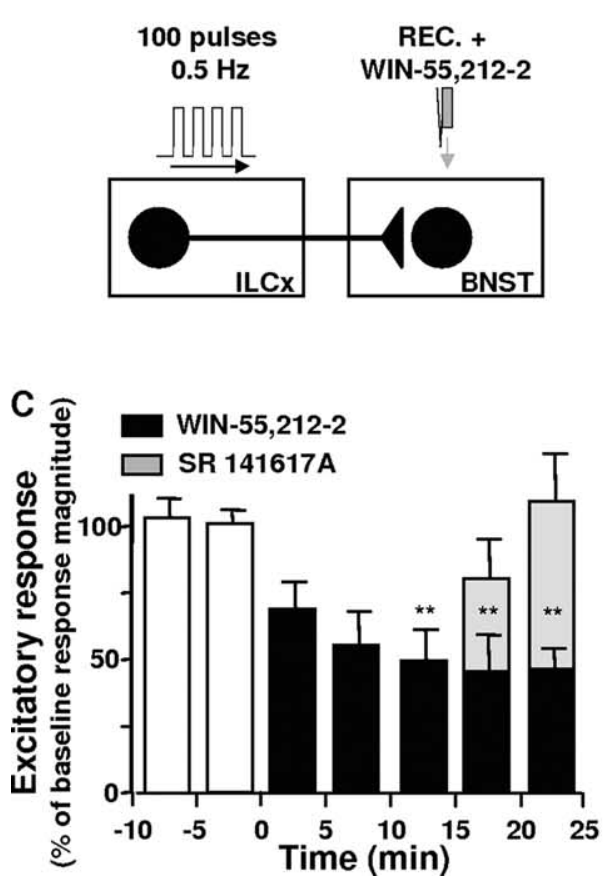

B
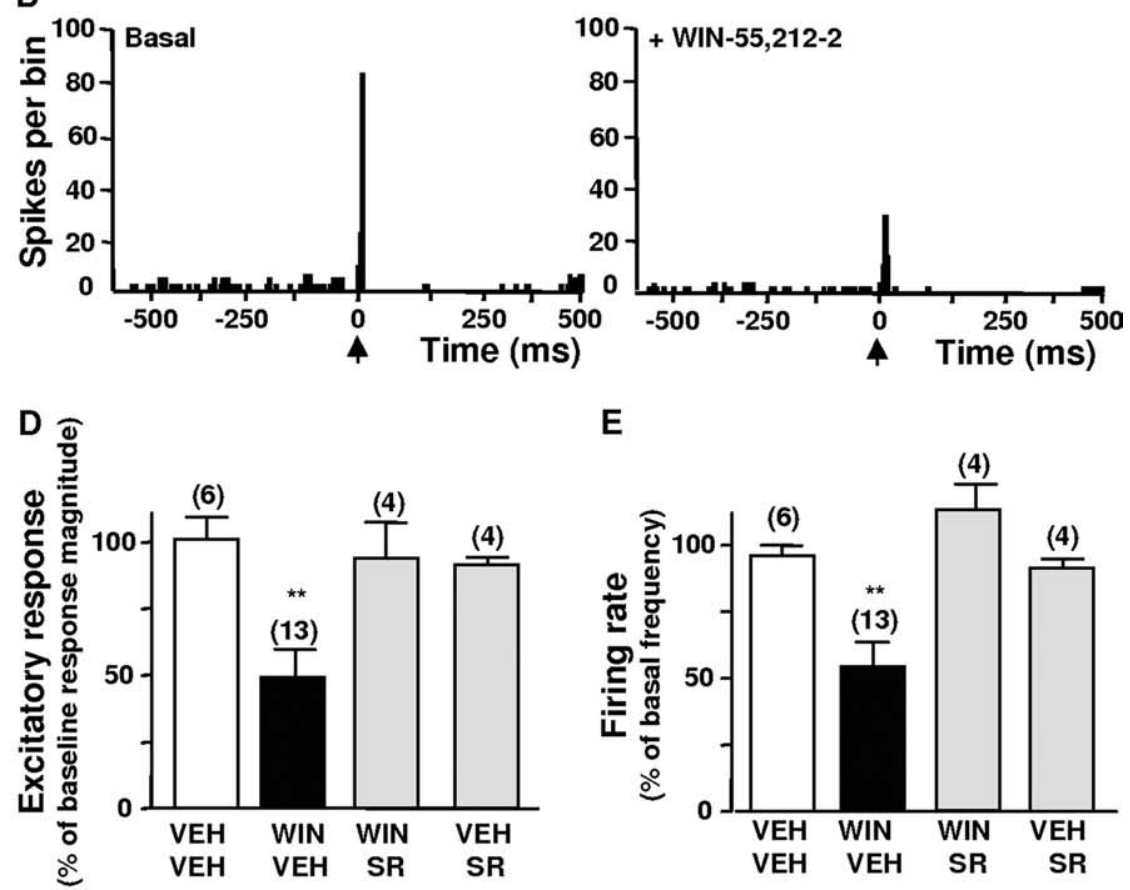

E

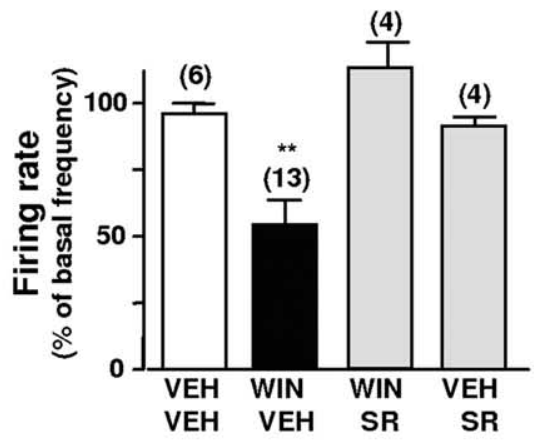

Figure 6. Effect of WIN 55212-2 microinjection into the BNST on neuronal impulse activity evoked by infralimbic cortex stimulation. $\boldsymbol{A}$, Diagram of the stimulation, microinfusion, and recording protocol used in this experiment. Here, the IL was stimulated with a 100-pulse train, and WIN 55212-2 (WIN, $500 \mu \mathrm{m}$ ) was microinfused within the BNST in a total volume of $20-30 \mathrm{nI}>15 \mathrm{~s}$. $\boldsymbol{B}$, Typical PSTHs showing ILCX-evoked excitation in a typical BNST neuron projecting to the VTA, before (Basal) and after intra-BNST infusion of WIN $55212-2$ (30 pmol/20 nl). Intra-BNST CB receptor activation inhibited excitation of BNST neurons evoked by ILCX stimulation. C, Time course of effects of intra-BNST WIN $55212-2$ infusion on evoked BNST neuronal impulse activity. Local infusion of WIN 55212-2 (infused at time 0, black bars) into the BNST induced a prolonged reduction of evoked impulse activity in BNST neurons compared with baseline (white bars). Data are expressed as percentage of mean response magnitude and are the mean \pm SEM. None of the cells returned to predrug level $(n=13)$; values are significantly different from baseline from 10 min after WIN 55212-2 (** $p<0.01$; ANOVA followed by Dunnett's test). Note the subsequent reversal by SR141716A (1 mg/kg, i.v.; injected at time 15 min, gray bars). $\boldsymbol{D}, \boldsymbol{E}$, Overall effects of intra-BNST infusion of VEH, WIN 55212-2, WIN 55212-2 plus systemic SR141716A and systemic SR141716A alone on evoked (D) and spontaneous (E) BNST neuronal impulse activity. The scores plotted are the change in response magnitude $(\boldsymbol{D})$ or firing frequency $(\boldsymbol{E})$ postdrug as a percentage of predrug rates. Intra-BNST WIN $55212-2$ injection induced a $50 \%$ inhibition of evoked response magnitude $(\boldsymbol{C})$ and spontaneous firing frequency (D). Note that SR141716A treatment had no effect by itself on evoked responses and spontaneous firing frequency. ANOVAs followed by Newman-Keuls tests for pairwise comparisons were performed for evoked responses and spontaneous firing frequency. ${ }^{* *} p<0.001$ versus control group (VEH treatments). Numbers of neurons recorded in each group are mentioned in parentheses above each histogram bar. REC, Recording electrode.

hypothalamic-pituitary-adrenal axis activity (Choi et al., 2007). Thus, although it remains difficult to predict the net functional and behavioral effects of activation of BNST on target brain regions, this study illustrates potential mechanisms by which glutamatergic input from the ILCx are able to enhance activity of VTA DA neurons via a relay in the BNST. Facilitation of the excitatory pathway from the ILCx to the BNST neurons projecting to the VTA may promote reward-seeking behaviors (Dumont et al., 2005).

Modulation of glutamatergic afferents plays an important role in regulating DA neuron activity, especially in mediating the switch from pacemaker-like activity to burst-firing (Overton and Clark, 1997). Importantly, burst-firing of DA neurons leads to larger, transient extracellular DA concentrations compared with single spiking (Gonon, 1988). Moreover, transient phasic increases of DA levels in target regions are associated with rewarding and alerting stimuli. The proportion of VTA DA neurons that receive $\mathrm{mPFC}$ input represents a minority of the total population (Carr and Sesack, 2000). The PL/Cg sends 90\% of the mPFC excitatory projections to the VTA and synapse primarily on GABAergic interneurons but also on mesocortical dopamine neurons (Carr and Sesack, 2000; Geisler et al., 2007). In contrast, the ILCx sends only $10 \%$ of the prefrontal excitatory projections to the VTA (Geisler et al., 2007). Thus, our finding that $>80 \%$ of the VTA DA cells (Table 1) respond to ILCx stimulation with an increased spiking probability strongly suggests that the BNST processes amplifies and actively distributes the excitatory drive from the ILCx to the majority of DA neurons. As a result, the recruitment of the ILCx-BNST pathway, by shaping the VTA DA neuronal pattern of activity and ultimately fine-tuning tonic versus phasic DA transmission, might enable or disrupt DA modulation of reward or stress responses (Georges and Aston-Jones, 2002; Wightman and Robinson, 2002; Dumont et al., 2005; Choi et al., 2007).

\section{GABAergic transmission in the BNST}

In the present study, we demonstrate that blocking $\mathrm{GABA}_{\mathrm{A}}$ receptors in BNST by local picrotoxin enhanced the probability of spike discharge evoked in BNST neurons by ILCx stimulation. These data raise questions about the potential role of feedforward inhibitory circuits including interneurons within the BNST and/or large projection from the GABAergic regions such as nucleus accumbens and central nucleus of the amygdala (Le Gal LaSalle et al., 1978) in regulating excitability of BNST neurons. The BNST sends a monosynaptic excitatory output to DA neurons in the VTA (Georges and Aston-Jones, 2002; Dumont and Williams, 2004). However, the majority of BNST neurons are GABAergic (70-90\%) (McDonald, 1983). Moreover, a particular feature characterizing the BNST is its large density of NMDA receptor (subunit, NMDAR1) immunoreactive terminals, form- 
ing symmetric synapses and displaying GABA immunoreactivity (Paquet and Smith, 2000). Thus, this population of presynaptic NMDA receptors, if activated by extrasynaptic glutamate diffusing from neighboring synapses (Kullmann and Asztely, 1998), may modulate the release of GABA. Our data with $\mathrm{GABA}_{\mathrm{A}}$ antagonist provide further support for the hypothesis that glutamatergic and GABAergic afferent pathways regulate BNST neuron population activity. However, we have no evidence that there is a high level of spontaneous GABA release that could contribute to tonic regulation of BNST neuronal activity. In fact, in the presence of picrotoxin, the basal activity of BNST neurons was not significantly affected. In addition, it is unknown whether $\mathrm{GABA}_{\mathrm{A}}$ receptors or other neurotransmitter systems participate in the inhibitory response evoked by ILCx stimulation. Additional studies are needed to address this issue.

\section{Cannabinoids in the BNST}

Activity at the CB1-R in reward- and stress-related behavior have been postulated as the basis of autoregulatory mechanisms compensating for excessive activation of postsynaptic neurons by glutamate (Lupica and Riegel, 2005; Rademacher and Hillard, 2007; Solinas et al., 2007). Presynaptic inhibition of glutamate release onto BNST neurons is mediated by activation of metabotropic glutamatergic receptors (Grueter and Winder, 2005) or alpha2noradrenergic receptors (Forray et al., 1999; Egli et al., 2005). Interestingly, Grueter et al. (2006) demonstrated that activation of group 1 metabotropic glutamate receptors in the BNST produces a depression of excitatory transmission that is sensitive to CB1-R antagonists and reduced in the CB1-R knock-out mouse. The present study shows that cannabinoids receptor activation reduces excitatory responses directly via local CB1-R signaling in BNST neurons projecting to the VTA. The fact that SR141617A per se failed to modify basal electrical activity of BNST neurons suggests that endogenous cannabinoids do not exert a tonic stimulatory action on these neurons. Our anatomical evidence reveal CB1-Rs on $90 \%$ of the presynaptic terminals issued from the ILCx, but we cannot exclude a localization of CB1-Rs on excitatory terminals from the ventral subiculum or on presynaptic GABAergic terminals.

As reported previously within the hippocampus, neocortex, and striatum (for review, see Piomelli, 2003), activation of CB1-Rs on GABAergic interneurons may remove inhibition on BNST neurons projecting to the VTA. However, this interaction between the CB1-Rs and GABAergic transmissions within the BNST appears negligible under physiological conditions, as the basal-steady state, and evoked activities are dramatically decreased by glutamatergic antagonists and CB1-Rs agonists.

The balance between inhibitory and excitatory neurotransmitter systems (i.e., glutamate, GABA, dopamine, or noradrena-

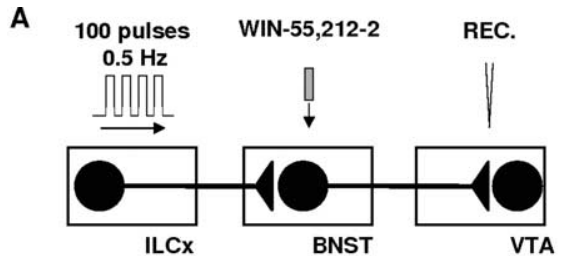

Before WIN-55,212-2 application During WIN-55,212-2 application

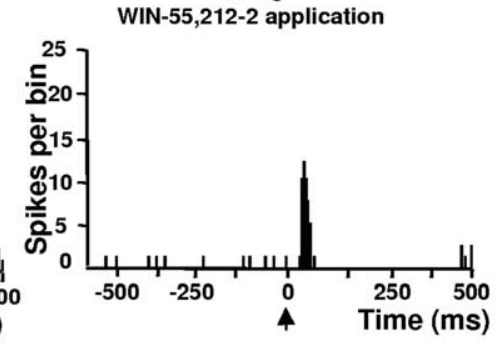

D

E

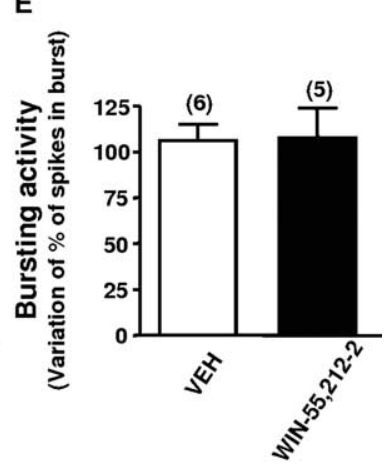

Figure 7. Infusion of WIN 55212-2 within the BNST inhibits the excitatory drive from the infralimbic cortex to VTA dopaminergic neurons. $\boldsymbol{A}$, Diagram of the stimulation, microinfusion, and recording protocol used in this experiment. Here, the IL was (WIN, $500 \mu \mathrm{m}$ ) was microinfused within the BNST in a total volume of $100 \mathrm{n}$ ( $\boldsymbol{C} \boldsymbol{E}$, Graphs illustrating the effects of microinjection of WIN 55212-2 within the BNST (black bars) on excitation ( $\boldsymbol{C}$ ) obtained after 作 bars). Numbers of neurons recorded in each group are mentioned in parentheses above each histogram bar. A two-tailed paired Student's $t$ tests was performed for excitatory response, firing rate, and bursting activity. ${ }^{* * *} p<0.001$. REC, Recording electrode.

line) shapes BNST neuron excitability (for review, see Forray and Gysling, 2004). Our observation that activation of CB1-Rs within the BNST alters the excitability of VTA DA neurons evoked by ILCx stimulation reveals that disturbances in this neural circuitry may underlie the aberrant emotional learning and processing observed in disorders such as addiction and pathological stress.

\section{Potential functional significance}

The BNST plays a critical role in responses to stress/anxiety and reward through a mechanism that involves excitatory glutamatergic transmission (Kash and Winder, 2006). Dumont and et al. (2005) highlighted the role of increased excitatory synaptic transmission in the BNST in both cocaine and food selfadministration. Moreover, inhibition of fast excitatory transmission in the BNST by injection of an AMPA receptor antagonist blunts anxiety responses (Walker and Davis, 1997), suggesting that regulation of glutamatergic transmission in this region may be an important target for anxiogenic stimuli. In conclusion, the present results disclose a novel and potent excitatory influence of ILCX on BNST neuronal function, which, through a relay to the VTA, reveals a new and potentially important reward circuit. In 


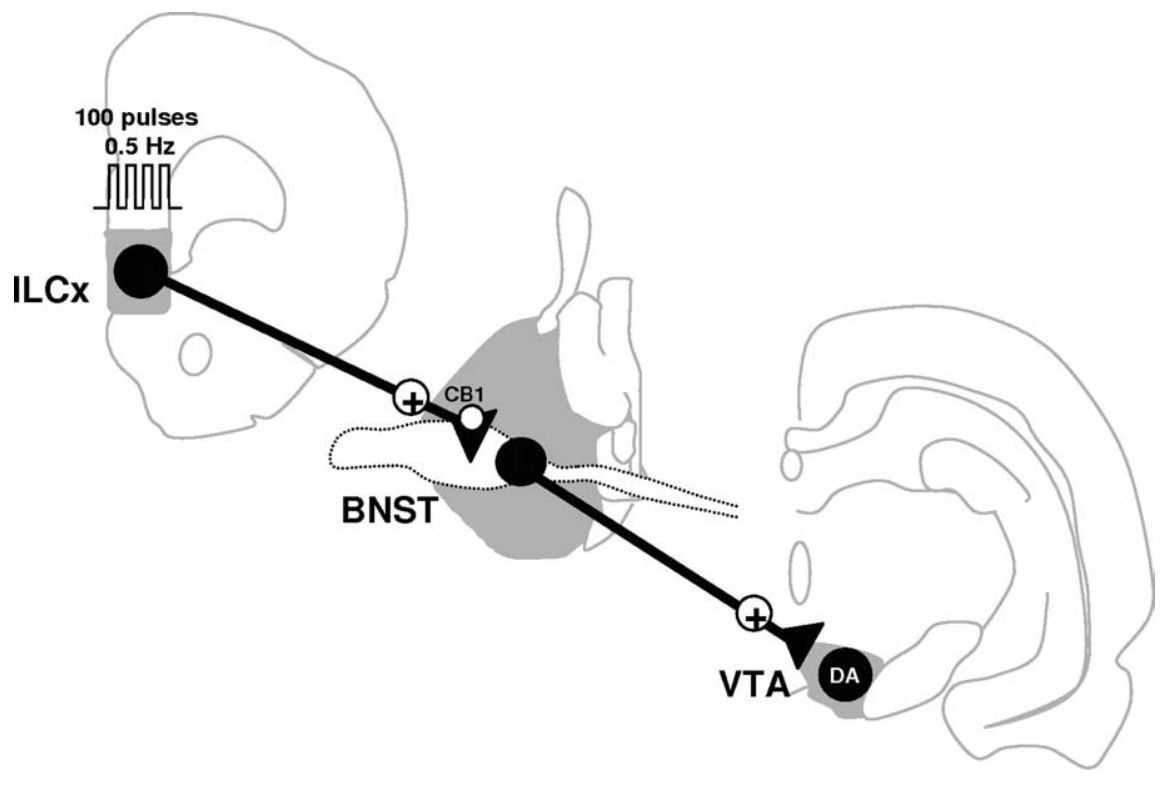

Figure 8. A model describing the neural circuitries by which the infralimbic cortex may modulate DA neuron activity. Electrical stimulation of the ILC $x$ activates excitatory afferents to the BNST. This in turn activates neurons in the BNST projecting to the VTA. As a result, there is a phasic activation of the midbrain DA neurons. In this model, we propose that the ILCX-BNST projection provides sufficient excitatory influence to activate the subpopulation of BNST neurons projecting to the VTA. Thus, inhibition of the excitatory drive within the BNST would lead to an inhibition of the excitatory responses of DA neurons evoked by ILC $x$ stimulation.

addition, although the DA system is classically associated with reward (Schultz, 2007), goal-directed behaviors can be altered by stress (Bowers et al., 1999). The final behavioral output results from interactions between stressful and rewarding stimuli. The BNST, driven by the ILCx, may be involved in processing both stress- and reward-related stimuli, which in turn influence goaldirected behaviors through the DA system. It is possible that one role of the BNST in the brain reward circuit is to adjust the output gain of DA neurons to boost the signaling of salient features and events represented in the ILCx. Our observation that activation of cannabinoid receptors within the BNST inhibits the excitatory response of VTA DA neurons evoked by ILCx stimulation reveals a novel aspect of the BNST and offers a new substrate for the effects of cannabinoids on animal model behavior.

\section{References}

Aston-Jones G, Harris GC (2004) Brain substrates for increased drug seeking during protracted withdrawal. Neuropharmacology 47:167-179.

Azad SC, Eder M, Marsicano G, Lutz B, Zieglgänsberger W, Rammes G (2003) Activation of the cannabinoid receptor type 1 decreases glutamatergic and GABAergic synaptic transmission in the lateral amygdala of the mouse. Learn Mem 10:116-128.

Bowers WJ, Attiast E, Amit Z (1999) Stress enhances the response to reward reduction but not food-motivated responding. Physiol Behav 67:777-782.

Carr DB, Sesack SR (2000) Projections from the rat prefrontal cortex to the ventral tegmental area: target specificity in the synaptic associations with mesoaccumbens and mesocortical neurons. J Neurosci 20:3864-3873.

Charara A, Smith Y, Parent A (1996) Glutamatergic inputs from the pedunculopontine nucleus to midbrain dopaminergic neurons in primates: phaseolus vulgaris-leucoagglutinin anterograde labeling combined with postembedding glutamate and GABA immunohistochemistry. J Comp Neurol 364:254-266.

Choi DC, Furay AR, Evanson NK, Ostrander MM, Ulrich-Lai YM, Herman JP (2007) Bed nucleus of the stria terminalis subregions differentially regulate hypothalamic-pituitary-adrenal axis activity: implications for the integration of limbic inputs. J Neurosci 27:2025-2034.

Delfs JM, Zhu Y, Druhan JP, Aston-Jones GS (1998) Origin of noradrener- gic afferents to the shell subregion of the nucleus accumbens: anterograde and retrograde tract-tracing studies in the rat. Brain Res 806:127-140.

Delfs JM, Zhu Y, Druhan JP, Aston-Jones G (2000) Noradrenaline in the ventral forebrain is critical for opiate withdrawal-induced aversion. Nature 403:430-434.

Domenici MR, Azad SC, Marsicano G, Schierloh A, Wotjak CT, Dodt HU, Zieglgänsberger W, Lutz B, Rammes G (2006) Cannabinoid receptor type 1 located on presynaptic terminals of principal neurons in the forebrain controls glutamatergic synaptic transmission. J Neurosci 26:5794-5799.

Dumont EC, Williams JT (2004) Noradrenaline triggers GABAA inhibition of bed nucleus of the stria terminalis neurons projecting to the ventral tegmental area. J Neurosci 24:8198-8204.

Dumont EC, Mark GP, Mader S, Williams JT (2005) Self-administration enhances excitatory synaptic transmission in the bed nucleus of the stria terminalis. Nat Neurosci 8:413-414.

Egli RE, Winder DG (2003) Dorsal and ventral distribution of excitable and synaptic properties of neurons of the bed nucleus of the stria terminalis. J Neurophysiol 90:405-414.

Egli RE, Kash TL, Choo K, Savchenko V, Matthews RT, Blakely RD, Winder DG (2005) Norepinephrine modulates glutamatergic transmission in the bed nucleus of the stria terminalis. Neuropsychopharmacology 30:657-668.

Erb S, Salmaso N, Rodaros D, Stewart J (2001) A role for the CRFcontaining pathway from central nucleus of the amygdala to bed nucleus of the stria terminalis in the stress-induced reinstatement of cocaine seeking in rats. Psychopharmacology 158:360-365.

Floresco SB, West AR, Ash B, Moore H, Grace AA (2003) Afferent modulation of dopamine neuron firing differentially regulates tonic and phasic dopamine transmission. Nat Neurosci 6:968-973.

Forray MI, Gysling K (2004) Role of noradrenergic projections to the bed nucleus of the stria terminalis in the regulation of the hypothalamicpituitary-adrenal axis. Brain Res Brain Res Rev 47:145-160.

Forray MI, Bustos G, Gysling K (1999) Noradrenaline inhibits glutamate release in the rat bed nucleus of the stria terminalis: in vivo microdialysis studies. J Neurosci Res 55:311-320.

Geisler S, Derst C, Veh RW, Zahm DS (2007) Glutamatergic afferents of the ventral tegmental area in the rat. J Neurosci 27:5730-5743.

Georges F, Aston-Jones G (2002) Activation of ventral tegmental area cells by the bed nucleus of the stria terminalis: a novel excitatory amino acid input to midbrain dopamine neurons. J Neurosci 22:5173-5187.

Gonon FG (1988) Nonlinear relationship between impulse flow and dopamine released by rat midbrain dopaminergic neurons as studied by in vivo electrochemistry. Neuroscience 24:19-28.

Grace AA, Bunney BS (1984) The control of firing pattern in nigral dopamine neurons: single spike firing. J Neurosci 4:2866-2876.

Grace AA, Floresco SB, Goto Y, Lodge DJ (2007) Regulation of firing of dopaminergic neurons and control of goal-directed behaviors. Trends Neurosci 30:220-227.

Grimsey NL, Goodfellow CE, Scotter EL, Dowie MJ, Glass M, Graham ES (2008) Specific detection of CB1 receptors; cannabinoid CB1 receptor antibodies are not all created equal! J Neurosci Methods 171:78-86.

Grueter BA, Winder DG (2005) Group II and III metabotropic glutamate receptors suppress excitatory synaptic transmission in the dorsolateral bed nucleus of the stria terminalis. Neuropsychopharmacology 30:1302-1311.

Grueter BA, Gosnell HB, Olsen CM, Schramm-Sapyta NL, Nekrasova T, Landreth GE, Winder DG (2006) Extracellular-signal regulated kinase 1-dependent metabotropic glutamate receptor 5-induced long-term depression in the bed nucleus of the stria terminalis is disrupted by cocaine administration. J Neurosci 26:3210-3219. 
Hammack SE, Mania I, Rainnie DG (2007) Differential expression of intrinsic membrane currents in defined cell types of the anterolateral bed nucleus of the stria terminalis. J Neurophysiol 98:638-656.

Healey JC, Winder DG, Kash TL (2008) Chronic ethanol exposure leads to divergent control of dopaminergic synapses in distinct target regions. Alcohol 42:179-190.

Herman JP, Cullinan WE (1997) Neurocircuitry of stress: central control of the hypothalamo-pituitary-adrenocortical axis. Trends Neurosci 20:78-84

Kash TL, Winder DG (2006) Neuropeptide Y and corticotropin-releasing factor bi-directionally modulate inhibitory synaptic transmission in the bed nucleus of the stria terminalis. Neuropharmacology 51:1013-1022.

Koob GF (2003) Neuroadaptive mechanisms of addiction: studies on the extended amygdala. Eur Neuropsychopharmacol 13:442-452.

Kullmann DM, Asztely F (1998) Extrasynaptic glutamate spillover in the hippocampus: evidence and implications. Trends Neurosci 21:8-14.

Lafourcade M, Elezgarai I, Mato S, Bakiri Y, Grandes P, Manzoni OJ (2007) Molecular components and functions of the endocannabinoid system in mouse prefrontal cortex. PLoS ONE 2:e709.

Le Gal LaSalle G, Paxinos G, Ben-Ari Y (1978) Neurochemical mapping of GABAergic systems in the amygdaloid complex and bed nucleus of the stria terminalis. Brain Res 155:397-403.

Lodge DJ, Grace AA (2006) The laterodorsal tegmentum is essential for burst firing of ventral tegmental area dopamine neurons. Proc Natl Acad Sci U S A 103:5167-5172.

Lupica CR, Riegel AC (2005) Endocannabinoid release from midbrain dopamine neurons: a potential substrate for cannabinoid receptor antagonist treatment of addiction. Neuropharmacology 48:1105-1116.

Maldonado R, Valverde O, Berrendero F (2006) Involvement of the endocannabinoid system in drug addiction. Trends Neurosci 29:225-232.

Marsicano G, Wotjak CT, Azad SC, Bisogno T, Rammes G, Cascio MG, Hermann H, Tang J, Hofmann C, Zieglgänsberger W, Di Marzo V, Lutz B (2002) The endogenous cannabinoid system controls extinction of aversive memories. Nature 418:530-534.

McDonald AJ (1983) Neurons of the bed nucleus of the stria terminalis: a golgi study in the rat. Brain Res Bull 10:111-120.

Murase S, Grenhoff J, Chouvet G, Gonon FG, Svensson TH (1993) Prefrontal cortex regulates burst firing and transmitter release in rat mesolimbic dopamine neurons studied in vivo. Neurosci Lett 157:53-56.

Omelchenko N, Sesack SR (2005) Laterodorsal tegmental projections to identified cell populations in the rat ventral tegmental area. J Comp Neurol 483:217-235.

Omelchenko N, Sesack SR (2007) Glutamate synaptic inputs to ventral tegmental area neurons in the rat derive primarily from subcortical sources Neuroscience 146:1259-1274.

Overton PG, Clark D (1997) Burst firing in midbrain dopaminergic neurons. Brain Res Brain Res Rev 25:312-334.

Paquet M, Smith Y (2000) Presynaptic NMDA receptor subunit immunoreactivity in GABAergic terminals in rat brain. J Comp Neurol 423:330-347.

Piomelli D (2003) The molecular logic of endocannabinoid signalling. Nat Rev Neurosci 4:873-884.

Rademacher DJ, Hillard CJ (2007) Interactions between endocannabinoids and stress-induced decreased sensitivity to natural reward. Prog Neuropsychopharmacol Biol Psychiatry 31:633-641.

Rainnie DG (1999) Neurons of the bed nucleus of the stria terminalis (BNST). Electrophysiological properties and their response to serotonin. Ann N Y Acad Sci 877:695-699.

Schultz W (2007) Behavioral dopamine signals. Trends Neurosci 30:203-210.

Seamans JK, Floresco SB, Phillips AG (1995) Functional differences between the prelimbic and anterior cingulate regions of the rat prefrontal cortex. Behav Neurosci 109:1063-1073.

Sesack SR, Pickel VM (1992) Prefrontal cortical efferents in the rat synapse on unlabeled neuronal targets of catecholamine terminals in the nucleus accumbens septi and on dopamine neurons in the ventral tegmental area. J Comp Neurol 320:145-160.

Solinas M, Yasar S, Goldberg SR (2007) Endocannabinoid system involvement in brain reward processes related to drug abuse. Pharmacol Res 8:8.

Spencer SJ, Buller KM, Day TA (2005) Medial prefrontal cortex control of the paraventricular hypothalamic nucleus response to psychological stress: possible role of the bed nucleus of the stria terminalis. J Comp Neurol 481:363-376.

Vertes RP (2004) Differential projections of the infralimbic and prelimbic cortex in the rat. Synapse 51:32-58.

Walker DL, Davis M (1997) Double dissociation between the involvement of the bed nucleus of the stria terminalis and the central nucleus of the amygdala in startle increases produced by conditioned versus unconditioned fear. J Neurosci 17:9375-9383.

Wightman RM, Robinson DL (2002) Transient changes in mesolimbic dopamine and their association with 'reward'. J Neurochem 82:721-735. 